
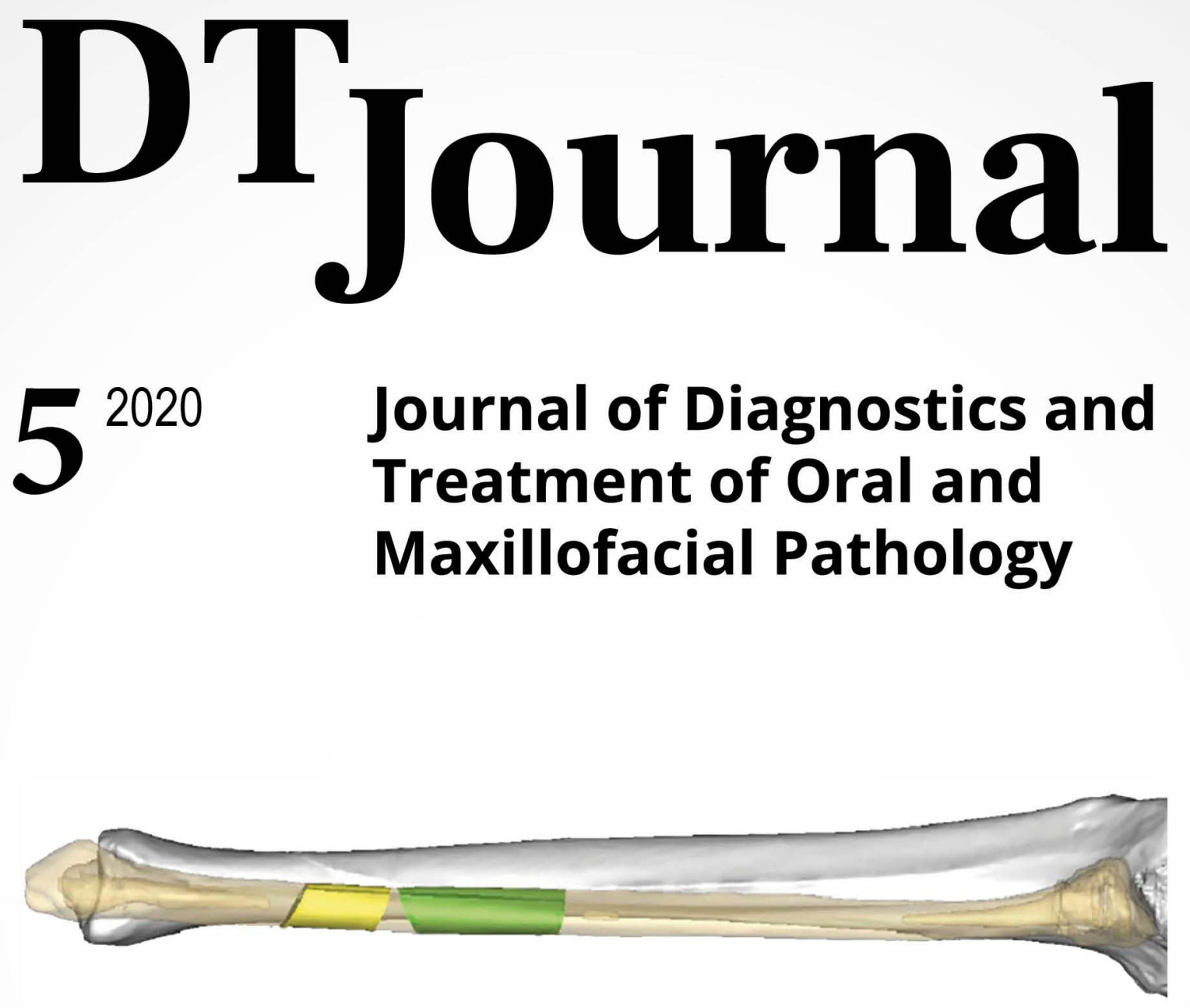

Editors

Oleksii Tymofieiev • Rui Fernandes (Kyiv, Ukraine • Jacksonville, FL, USA)

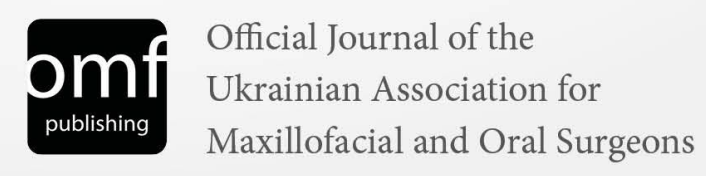

DTJournal.org 

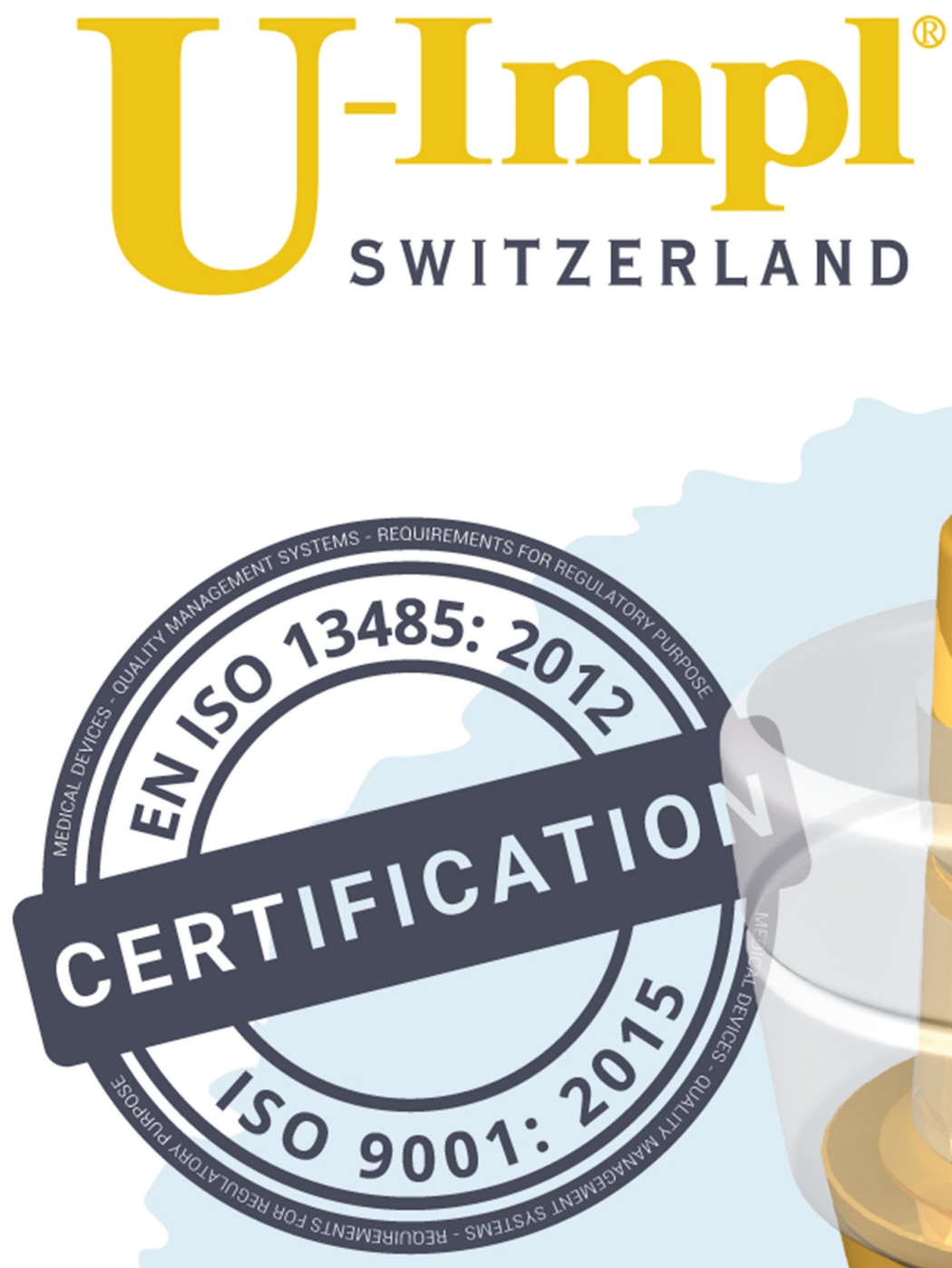

№ R3M 804252 B2

Сертифікат відповідності технічного регламенту щодо медичних виробів 


\section{About the Journal: Aims and Scope

\section{Official Title}

Journal of Diagnostics and Treatment of Oral and Maxillofacial Pathology

\section{Standard Abbreviation: ISO 4}

J. Diagn. Treat. Oral Maxillofac. Pathol.

\section{International Standard Serial Number (ISSN) \\ Print ISSN 2519-2086 | Online ISSN 2522-1965}

\section{Aims \& Scope}

This is a monthly peer-reviewed oral and maxillofacial surgery journal focused on: Microvascular and jaw reconstructive surgery, dental implants, salivary gland tumors/diseases, TMJ lesions, virtual surgical planning, implementation of ultrasonography into the practice of oral and maxillofacial surgeons.

\section{Editorial Board (EB) Composition}

- EB shows significant geographic diversity representing 24 opinion leaders from 13 countries: Brazil, Canada, Colombia, Greece, Hong Kong (SAR, China), India, Israel, Italy, Slovak Republic, Spain, Ukraine, United Arab Emirates, and United States.

- The majority of the EB Members have a discernible publication history in Scopus, Web of Science, and journals with a high impact factor.

- The publication records of all EB members are consistent with the stated scope and published content of the journal.

- The journal has a several full-time professional editors.

\section{Frequency}

12 print/online issues a year (from January 2020)

\section{Publication History}

2017: 4 issues a year

2018: 4 issues a year

2019: 10 issues a year

2020: 12 issues a year

\section{Publishing Model}

Journal combines a hybrid and delayed open access publishing models. The articles of all types, except Editorials, are immediately in open access. Editorials became an open access publication too after 3-month embargo period.

\section{Article Processing Charge (APC)}

During hard times of Covid-19 pandemic our journal trying to support authors by reducing the APC by $50 \%$. And by the end of August 2020 the APC will be 100 USD and 50 USD (excluding taxes) depending on the article's type. Details at website: dtjournal.org.
12 Types of Articles Currently Published by the Journal Editorials/Guest Editorials, Images in Oral \& Maxillofacial Surgery, Case Reports/Case Series, Original Articles, Review Articles, Discussions, Paper Scans (synonyms: Review of Articles, Literature Scan), Book Scans (synonym: Book Reviews), Letters to the Editor (synonym: Letters), and Viewpoints.

\section{Registration: Ministry of Justice of Ukraine}

Registration: July 28, 2016

Re-Registration: May 21, 2019 (Certificate: КВ \# 23999-13839ПР)

\section{Co-Founders}

1. Shupyk National Medical Academy of Postgraduate Education.

2. Private Higher Educational Establishment "Kyiv Medical University."

3. OMF Publishing, Limited Liability Company.

\section{Publisher}

OMF Publishing, LLC is an academic publisher focused on medical and linguistic sciences.

Address: 13-A Simferopolska Street, Office 121, Kyiv 02096, Ukraine. Tel.: +380632931813.

\section{Crossref Membership}

OMF Publishing, LLC is a member of Publishers International Linking Association, Inc. which doing business as a Crossref. OMF Publishing`s active membership: From February 2017 to present.

\section{Official Journal of}

Ukrainian Association for Maxillofacial and Oral Surgeons

\section{Ukrainian Association for Maxillofacial and Oral Surgeons (UAMOS)}

Address: 4-A Profesora Pidvysotskoho Street, Kyiv 01103, Ukraine. Tel., fax: +38 0445283517 .

Website: uamos.org.

\section{Subscription Index}

In Ukraine: 60077 | In Donetsk/Luhansk Regions: 88263. See page A5.

\section{(c) 2020 OMF PUBLISHING, LLC}




\section{Editor in Chief}

Oleksii O. Tymofieiev, ScD

(Kyiv, Ukraine)

\section{Deputy Editor in Chief}

Rui P. Fernandes, MD, DMD, FACS, FRCS(Ed)

(Jacksonville, Florida, United States)

\section{Section Editors}

Bone Augmentation Techniques

Nardy Casap, MD, DMD

(Jerusalem, Israel)

Craniofacial Deformities

Sunil Richardson, MDS

(Nagercoil, Tamil Nadu, India)

Facial Feminization Surgery

Kyle Keojampa, MD, FACS

(Los Angeles, California, United States)

Facial Plastic Surgery

Tirbod Fattahi, MD, DDS, FACS

(Jacksonville, Florida, United States)

Head \& Neck Oncologic Surgery

Todd C. Hanna, MD, DDS, FACS

(New York, New York, United States)
Head \& Neck Radiology

Anil T. Ahuja, MBBS, MD, FRCR, FHKCR, FHKAM

(Hong Kong, SAR, China)

Images in Oral \& Maxillofacial Surgery

Camilo Mosquera, DDS

(Bogotá, D.C., Colombia)

Orthognathic Surgery

Mario Brinhole

(São Paolo, São Paolo, Brazil)

Robotic Surgery

Salam O. Salman, MD, DDS, FACS

(Jacksonville, Florida, United States)

TMJ Lesions/Disorders

Belmiro C. Vasconcelos, DDS, PhD

(Recife, Pernambuco, Brazil)

Editorial Board Members

Oleh M. Antonyshyn, MD, FRCS(C)

(Toronto, Ontario, Canada)

Anthony M. Bunnell, MD, DMD, FACS

(Jacksonville, Florida, United States)

Nur A. Hatab, DMD, PhD

(Ras Al Khaimah, United Arab Emirates)

Andrey V. Kopchak, ScD

(Kyiv, Ukraine)
Olindo Massarelli, MD, PhD, FEBOMFS

(Sassari, Italy)

Daniel Robles Cantero, DDS, MSc (Madrid, Spain)

Peter Stanko, MD, PhD

(Bratislava, Slovak Republic)

Olexander O. Tymofieiev, ScD

(Kyiv, Ukraine)
Natalia O. Ushko, ScD

(Kyiv, Ukraine)
Web \& Social Media Editor

João L. Monteiro, DDS

(Boston, Massachusetts, United States)
Director, Journal Development Department

Evangelos G. Kilipiris, DMD

(Thessaloniki, Greece | Bratislava, Slovak Republic)
Managing Editor

Ievgen I. Fesenko, PhD

(Kyiv, Ukraine) 


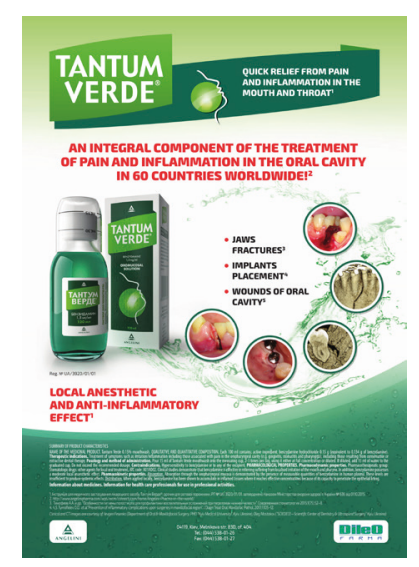

\section{TANTUM VERDE ${ }^{\circledR}$ \\ INFORMATION LEAFLET \\ for the medicinal product}

\section{Composition:}

active substance: benzydamine hydrochloride;

$100 \mathrm{~mL}$ of solution contain benzydamine hydrochloride $0.15 \mathrm{~g}$;

excipients: ethanol 96\%, glycerol, methyl parahydroxybenzoate (E 218), flavor (menthol), saccharin, sodium hydrocarbonate, Polysorbate 20, Quinoline Yellow (E 104), Patent Blue V (E 131), purified water.

Dosage form. Oromucosal solution.

Basic physical and chemical properties: a clear green liquid with a typical mint flavor.

Pharmacotherapeutic group. Dental preparations. Other agents for local oral treatment.

ATC code: A01A D02.

\section{Pharmacological properties.}

Pharmacodynamics.

Benzydamine is a non-steroidal anti-inflammatory drug (NSAID) with analgesic and antiexudative properties.

Clinical studies have shown that benzydamine is effective in the relief of symptoms accompanying localized irritation conditions of the oral cavity and pharynx. Moreover, benzydamine has anti-inflammatory and local analgesic properties, and also exerts a local anesthetic effect on the oral mucosa.

\section{Pharmacokinetics.}

Absorption through the oral and pharyngeal mucosa has been proven by the presence of measurable quantities of benzydamine in human plasma. However, they are insufficient to produce any systemic pharmacological effect. The excretion occurs mainly in urine, mostly as inactive metabolites or conjugated compounds.

When applied locally, benzydamine has been shown to cumulate in inflamed tissues in an effective concentration due to its ability to permeate through the mucous membrane.

\section{Clinical particulars.}

Indications.

Symptomatic treatment of oropharyngeal irritation and inflammation; to relieve pain caused by gingivitis, stomatitis, pharyngitis; in dentistry after tooth extraction or as a preventive measure.

\section{Contraindications.}

Hypersensitivity to the active substance or to any other ingredients of the product.

Interaction with other medicinal products and other types of interaction.

No drug interaction studies have been performed.

\section{Warnings and precautions.}

If sensitivity develops with long-term use, the treatment should be discontinued and a doctor should be consulted to get appropriate treatment.

In some patients, buccal/pharyngeal ulceration may be caused by severe pathological processes. Therefore, the patients, whose symptoms worsen or do not improve within 3 days or who appear feverish or develop other symptoms, should seek advice of a physician or a dentist, as appropriate.

Benzydamine is not recommended for use in patients hypersensitive to acetylsalicylic acid or other non-steroidal anti-inflammatory drugs (NSAIDs).

The product can trigger bronchospasm in patients suffering from or with a history of asthma. Such patients should be warned of this.

For athletes: the use of medicinal products containing ethyl alcohol might result in positive antidoping tests considering the limits established by some sports federations. 
Use during pregnancy or breast-feeding

No adequate data are currently available on the use of benzydamine in pregnant and breastfeeding women. Excretion of the product into breast milk has not been studied. The findings of animal studies are insufficient to make any conclusions about the effects of this product during pregnancy and lactation.

The potential risk for humans is unknown.

TANTUM VERDE should not be used during pregnancy or breast-feeding.

Effects on reaction time when driving or using machines When used in recommended doses, the product does not produce any effect on the ability to drive and operate machinery.

\section{Method of administration and doses.}

Pour $15 \mathrm{~mL}$ of TANTUM VERDE solution from the bottle into the measuring cup and gargle with undiluted or diluted product $(15 \mathrm{~mL}$ of the measured solution can be diluted with $15 \mathrm{~mL}$ of water). Gargle 2 or 3 times daily. Do not exceed the recommended dose.

\section{Children.}

The product should not be used in children under 12 years due to a possibility of ingestion of the solution when gargling.

\section{Overdosage.}

No overdose has been reported with benzydamine when used locally. However, it is known that benzydamine, when ingested in high doses (hundreds times higher than those possible with this dosage form), especially in children, can cause agitation, convulsions, tremor, nausea, increased sweating, ataxia, and vomiting. Such acute overdose requires immediate gastric lavage, treatment of fluid/salt imbalance, symptomatic treatment, and adequate hydration.

\section{Adverse reactions.}

Within each frequency group, the undesirable effects are presented in order of their decreasing seriousness.

Adverse reactions are classified according to their frequency: very common $(\geq 1 / 10)$; common $(\geq 1 / 100$ to $<1 / 10)$; uncommon $(\geq 1 / 1,000$ to $<1 / 100)$; rare $(\geq 1 / 10,000$ to $<1 / 1,000)$; very rare $(<1 / 10,000)$; frequency unknown (cannot be estimated from the available data).
Gastrointestinal disorders: rare - burning mouth, dry mouth; unknown - oral hypesthesia, nausea, vomiting, tongue edema and discoloration, dysgeusia.

Immune system disorders: rare - hypersensitivity reaction, unknown - anaphylactic reaction.

Respiratory, thoracic and mediastinal disorders: very rare-laryngospasm; unknown - bronchospasm.

Skin and subcutaneous tissue disorders: uncommon photosensitivity; very rare - angioedema; unknown - rash, pruritus, urticaria.

Nervous system disorders: unknown - dizziness, headache.

TANTUM VERDE contains methyl parahydroxybenzoate, which can cause allergic reactions (including delayed-type reactions).

Shelf life. 4 years.

\section{Storage conditions.}

Do not store above $25^{\circ} \mathrm{C}$. Keep out of reach of children.

\section{Packaging.}

$120 \mathrm{~mL}$ of solution in a bottle with a measuring cup; 1 bottle per cardboard box.

Dispensing category.

Over-the-counter medicinal product.

\section{Manufacturer.}

Aziende Chimiche Riunite Angelini Francesco A.C.R.A.F. S.p.A., Italy.

Location of the manufacturer and its business address. Via Vecchia del Pinocchio, 22 - 60100 Ancona (AN), Italy.

\section{Date of the last revision of the text.}

September 26, 2018.

Information leaflet is

APPROVED by

Order of the

Ministry of Health of Ukraine

No. 636 dated 01.10.2015

Registration Certificate

No. UA/3920/01/01 


\section{Subscription in Ukraine \\ MAY $2020 \cdot$ VOLUME $4 \cdot$ ISSUE 5}

Frequency of the Journal of Diagnostics and Treatment of Oral and Maxillofacial Pathology:

12 issues (synonym: numbers) per year.

Subscription index in Ukraine: 60077.

Subscription index for Donetsk and Luhansk Regions: 88263.
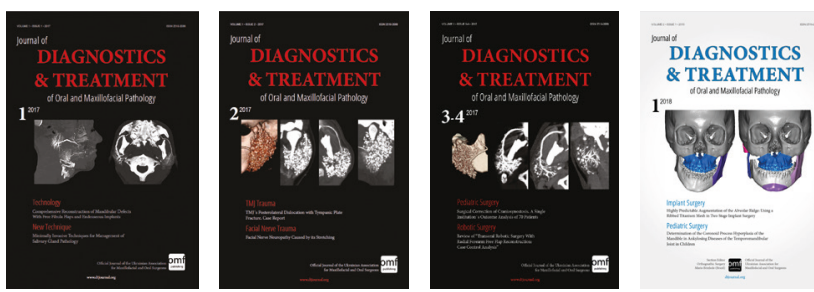

hratd DIAGNOSTICS \& TREATMENT
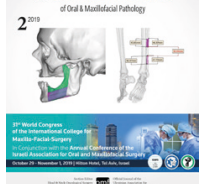

$\overline{\text { pmexid }}$

DIAGNOSTIC

\& TR

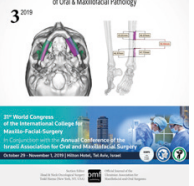

Diagnostics

DIAGNOSTICS
\& TREATMENT

$4^{20}$,
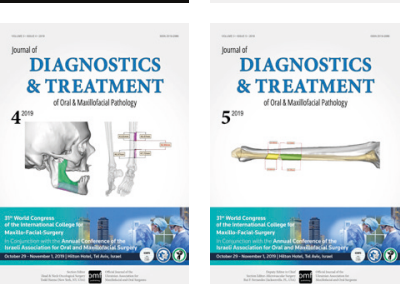

$5^{2 x}$
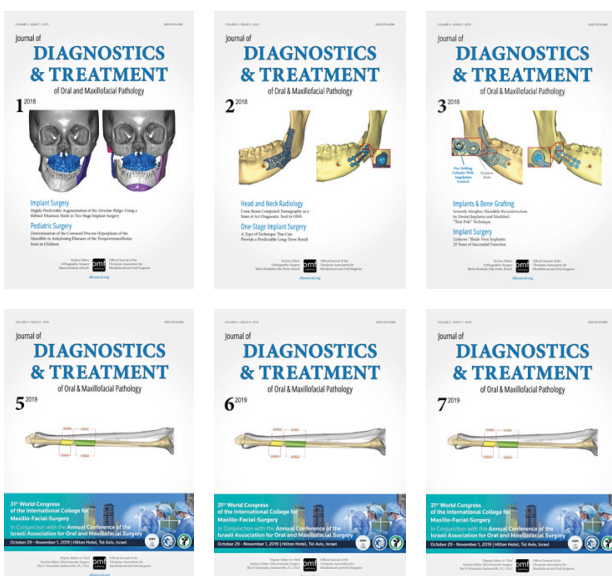

$6^{m}$

$+2$
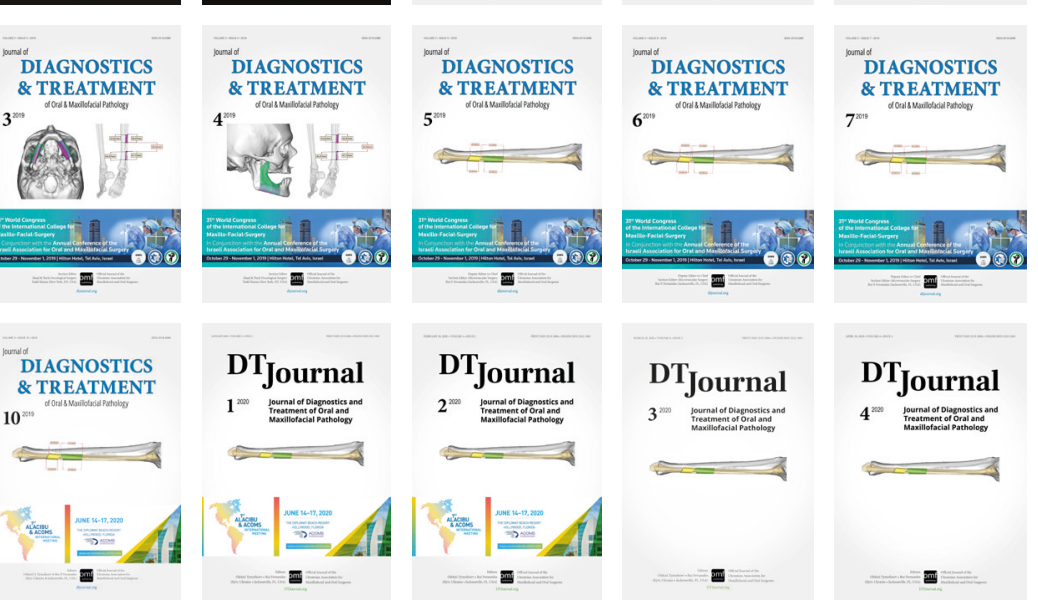

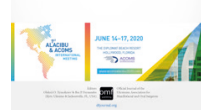

…

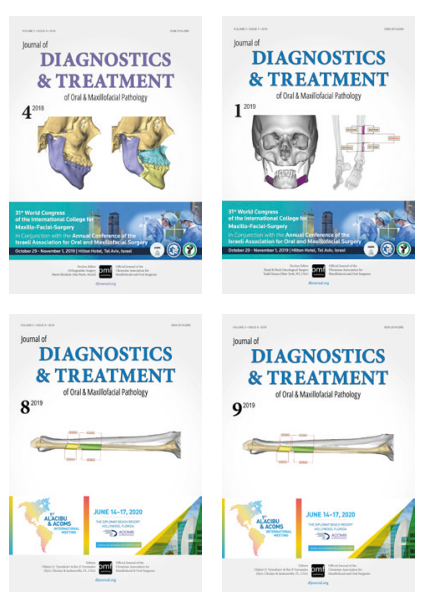

DT Journal

5 =

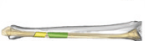

Three ways of individual/institutional subscription of print version of the Journal:

1. At Ukrposhta post at the territory of Ukraine.

2. At the website www.presa.ua.

3. At the website www.dtjournal.org (from September 1, 2020).

\begin{tabular}{|c|c|}
\hline Issues & Fee in 2020 \\
\hline 1 issue & $\$ 4^{12}$ USD $\left(103^{08} \mathrm{UAH}\right)$ \\
\hline 3 issues & $\$ 12^{36} \mathrm{USD}\left(309^{24} \mathrm{UAH}\right)$ \\
\hline 6 issues & $\$ 24^{73} \mathrm{USD}\left(618^{48} \mathrm{UAH}\right)$ \\
\hline 12 issues & $\$ 49^{47} \mathrm{USD}\left(1,236^{96} \mathrm{UAH}\right)$ \\
\hline
\end{tabular}




\section{Content}

of the Volume 4 • Issue 5 - May 2020

Benign Head and Neck Conditions: Case Series + Video

Images in Oral and Maxillofacial Surgery
A1 Publisher \& Editorial Office Information

\section{A2 Editorial Board}

A5 Subscription in Ukraine

A6 Content, Courtesy, \& Erratum

79 Gigantic Dentigerous Cysts Associated with the Ectopic/Impacted Upper Third Molars: Computed Tomography Analysis of Nasolacrimal Duct and Osteomeatal Complex Obstructions and Review of Literature Tetiana M. Babkina, Oleg G. Shekera, Yulia O. Storozhchuk, Kyrylo I. Telukha, Oleksandr A. Nozhenko, Ievgen I. Fesenko, Valentyna I. Zaritska, \& Pavlo P. Snisarevskyi

95 Post-Traumatic Facial and Intracranial Emphysema Tetiana O. Shamova \& Ruslan A. Pavlenko

\section{DT Journal

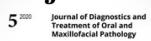 \\ $\stackrel{2}{2}$

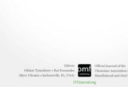 \\ COURTESY}

Journal's cover image (virtual surgical planning for a segmental mandibular reconstruction with fibula transplant) is courtesy of Rui P. Fernandes, MD, DMD, FACS, FRCS.

Image was taken from the article: Fernandes RP, Quimby A, Salman S. Comprehensive reconstruction of mandibular defects with free fibula flaps and endosseous implants. J Diagn Treat Oral Maxillofac Pathol 2017;1(1):6-10. 


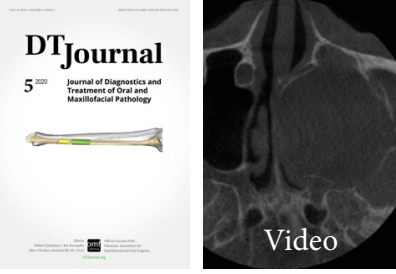

Benign Head and Neck Conditions: Case Series + Video

\title{
Gigantic Dentigerous Cysts Associated with the Ectopic/Impacted Upper Third Molars: Computed Tomography Analysis of Nasolacrimal Duct and Osteomeatal Complex Obstructions and Review of Literature
}

\author{
Tetiana M. Babkina ${ }^{a}$, Oleg G. Shekerab, Yulia 0. Storozhchuk, Kyrylo I. Telukhad, Oleksandr A. Nozhenkoe, \\ levgen I. Fesenkof, , Valentyna I. Zaritskå, \& Pavlo P. Snisarevskyi
}

\section{SUMMARY}

We report the cases with giant dentigerous cysts (synonym: follicular cysts) of the maxillary sinus which caused ophthalmologic, neurologic, and nasal disturbances.

Case 1: A 44-year-old female with osteomeatal complex obstruction and severe headaches due to giant dentigerous cyst associated with impacted upper left wisdom tooth. An air-fluid level and middle turbinate compression with intact lower turbinate became the characteristic features of the case which reviewed in the publications.

Case 2: A 60-year-old woman with complete acquired nasolacrimal duct and osteomeatal complex obstruction due to gigantic dentigerous cyst. It's a first ever reported case when the cyst originated from ectopic upper third molar and led to the permanent left eye epiphora and left side nasal obstruction.

In both cases the consecutive pre-operative cone-beam computed tomography is presented and comparison of attenuation coefficient of the cystic content is analyzed. Management of the cases is described, surgical techniques and literature is reviewed; 1-year follow-up period is highlighted.

\footnotetext{
Kyiv, Ukraine

a ScD, Professor; Head, Department of Radiology, Shupyk National Medical Academy of Postgraduate Education.

${ }^{\text {b }} \mathrm{ScD}$, Professor; Director, Institute of Family Medicine, Shupyk National Medical Academy of Postgraduate Education.

${ }^{c}$ Assistant Professor, Department of Radiology, Shupyk National Medical Academy of Postgraduate Education.

${ }^{d}$ Radiologist, Kolomiychenko Institute of Otolaryngology of the National Academy of Medical Sciences of Ukraine.

e Oral Surgeon, Center of Maxillofacial Surgery and Dentistry, Kyiv Regional Clinical Hospital.

f PhD, Assistant Professor, Department of Oral and Maxillofacial Surgery, Private Higher Educational Establishment "Kyiv Medical University."

${ }^{9} \mathrm{PhD}$, Associate Professor, Department of Pathology, Shupyk National Medical Academy of Postgraduate Education.

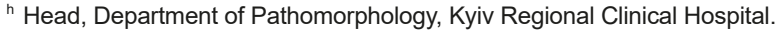

\footnotetext{
* Corresponding author's address: Department of Oral and Maxillofacial Surgery, Private Higher Educational Establishment "Kyiv Medical University." 7 Antona Tsedika Street, Kyiv 02000, Ukraine. Tel.: +380632931813

E-mail: i.i.fesenko@dtjournal.org (levgen Fesenko)
}

Please cite article as: Babkina TM, Shekera OG, Storozhchuk YO, Telukha KI, Nozhenko OA, Fesenko II, Zaritska VI, Snisarevskyi PP. Gigantic dentigerous cysts associated with the ectopic/impacted upper third molars: computed tomography analysis of nasolacrimal duct and osteomeatal complex obstructions and review of literature. J Diagn Treat Oral Maxillofac Pathol 2020;4(5):79-94.

Paper received 10 March 2020

Accepted 2 April 2020

Available online 29 May 2020

httpi://dx.doi.org/10.23999/j.dtomp.2020.5.1.

(c) 2020 OMF Publishing, LLC. This is an open access article under the CC BY license (http://creativecommons.org/licenses/by-nc/4.0/). 


\section{INTRODUCTION}

Nasolacrimal duct obstruction (NLDO) is a congenital or acquired pathologic condition usually manifesting with epiphora (synonyms: tearing, watering eye) due blockage of tear outflow though the nasolacrimal duct. ${ }^{1}$ Partial and complete NLDO are distinguished. ${ }^{2}$ Among causes of NLDO are: dacryolith (synonym: lacrimal stone) ${ }^{2}$ formation, trauma, and growing neoplasms. ${ }^{3}$ Traumatic etiology of NLDO can be established after nasoorbito-ethmoidal fractures, ${ }^{4}$ medial maxillectomy, ${ }^{5}$ secondary to maxillofacial hardware placement, ${ }^{3}$ etc. Among malignant neoplasm which led to the NLDO, a undifferentiated sinonasal carcinoma was reported, ${ }^{6}$ among benign - giant radicular $^{7}$ and dentigerous cysts ${ }^{8-12}$. Moreover, a NLDO caused by a canine apex was presented. ${ }^{13}$ The main symptom of the NLDO is "epiphora" which is commonly described as a tearing or watering eye.

Dentigerous cysts (synonym: follicular cysts) ${ }^{14}$ belong to the odontogenic group of cysts in which they count 18.1 percent of cases. ${ }^{15}$ The term "dentigerous cyst" was proposed by English surgeon and pathologist James Paget in 1853 and literally means "tooth bearing cyst." ${ }^{16}$ Its synonym "a follicular cyst" is also very popular for it explains that cystic wall arises from the follicle of a tooth that has failed to erupt. ${ }^{14,17}$ Among all number of dentigerous cyst, only $30 \%$ of them occur in the maxilla. ${ }^{18}$ From the maxillary dentigerous cyst cases the majority was noted around the impacted canines and far less had arisen from the follicles of the impacted/ectopic upper third molars, among which the bilateral cases are also reported. ${ }^{17}$

To our knowledge, 6 cases in the English language literature have described the NLDO caused by growing dentigerous cyst. ${ }^{8-12}$ But none of them reported the NLDO following growth of dentigerous cyst which originated from the ectopic upper third molar's follicle.

So, the purpose of our paper is to highlight, compare, and analyze two cases:

1. A giant follicular cyst of the maxillary sinus in a 44-year-old female with osteomeatal complex obstruction and unusual intracystic air-fluid level.

2. A gigantic dentigerous cyst associated with ectopic upper wisdom tooth in a 60 -year-old female with a complete acquired nasolacrimal duct and osteomeatal complex obstructions and chronic left eye epiphora.

\section{CASE 1}

In July 2014, a 44-year-old female was referred by neurologist to the Center of Maxillofacial Surgery. The patient had a long history of headaches; and cone-beam computed tomography (CBCT) (Planmeca ProMax 3D Max, Planmeca, Finland) showed a giant dentigerous cyst associated with impacted upper left wisdom tooth (Fig 1). Thickness of CT slices was $0.15 \mathrm{~mm}$. The cyst occupied the entire left maxillary sinus, compressed the left middle turbinate, and prolapsed to the upper left nasal meatus. Also, the air-fluid level was visualized (Fig 1B, C): lower and middle part of the cyst was filled with a content which attenuation coefficient varies from -195.2 to -20.4 Hounsfield units (HU), upper part contained air (attenuation coefficient varies from -911.8 to $-790 \mathrm{HU})$. Attenuation coefficient measurements have been performed in 5 different areas of each type of content. In our opinion, taking into account that there was no evidence of previous intracystic infection, the presence of intracystic air component can be a result of cystic wall microperforation(s) in area of the left maxillary ostium.

VIDEO 1 (Supplemental Video Content) shows sequence of axial CBCT scans. Slice on the 14th second of the video demonstrates the intact, opacified, oval shape nasolacrimal canals measured $0.54 \times 0.31 \mathrm{~cm}$ (right) and $0.62 \times 0.35 \mathrm{~cm}$ (left). Thickness of the cystic walls varied from 0.67 to $4.37 \mathrm{~mm}$; and hyperplasia (mucosal thickening reached $4.9 \mathrm{~mm}$ ) of the Schneiderian membrane (synonyms: mucoperiosteum, maxillary sinus membrane $)^{19}$ was noted in all areas of the sinus. Video is available in the page of the full-text article on dtjournal.org and in the YouTube channel, available at https://youtu.be/yigKLrEQMlw. Total video`s duration: 37 seconds.

Removal of the cystic lesion with upper third molar (Fig 2A, B) was performed (Oleksandr A. Nozhenko) under nasotracheal intubation using Caldwell-Luc approach at the anterolateral aspect of the left maxillary sinus. During the enucleation of the cyst, its fluid content was evacuated. After creation of the artificial naso-antral passage $(5 \times$ 

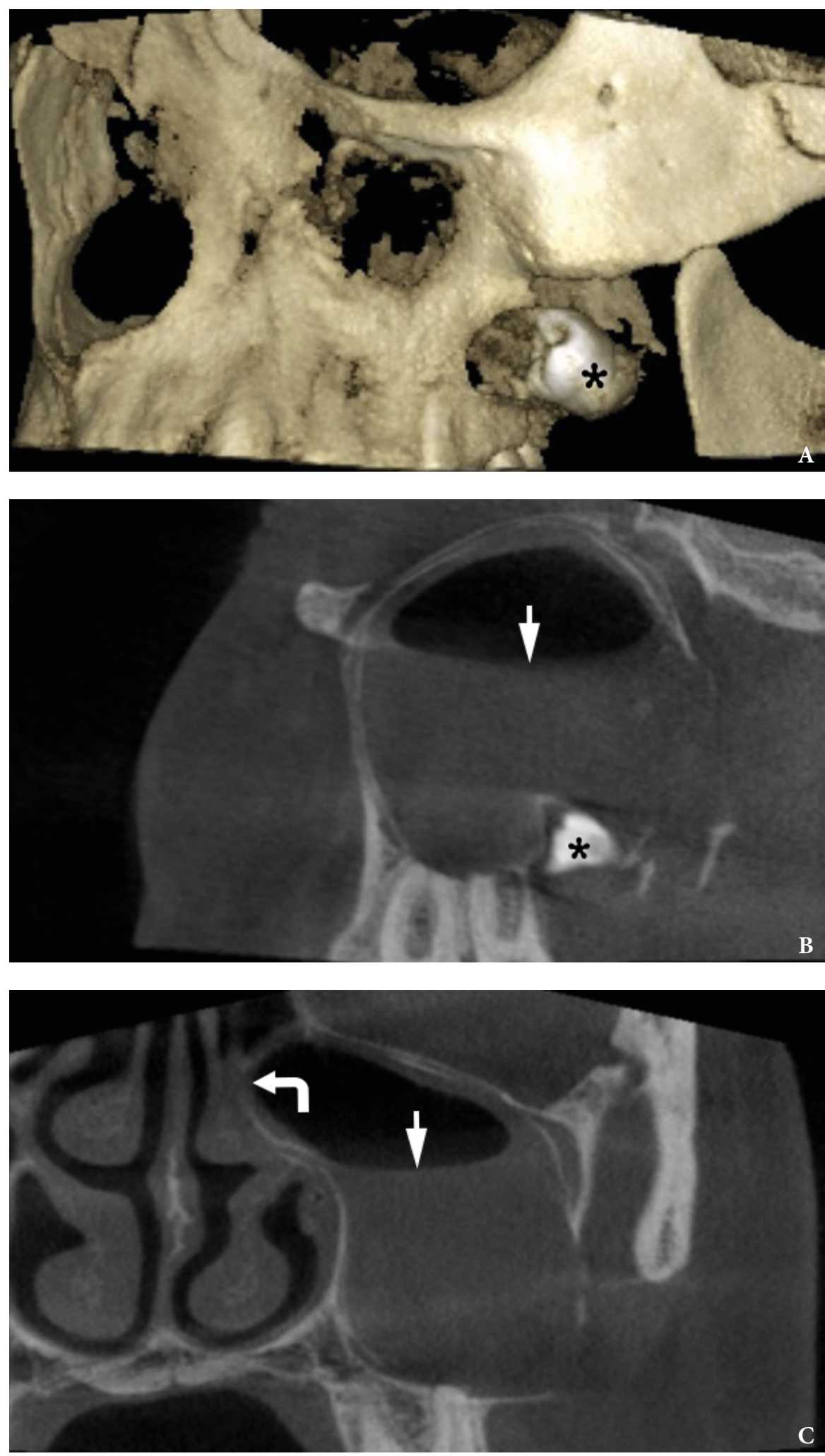

FIGURE 1. Case 1. CBCT (A-C) of a 44-year-old female with a giant dentigerous cyst associated with impacted upper left wisdom tooth (asterisk). Notes that cyst is occupying the entire left maxillary sinus and compressed the left middle turbinate (curved arrow). Also, visualized the air-fluid level (arrow): lower and middle part of the cyst filled with a fluid content which attenuation coefficient varies from -195.2 to -20.4 HU, upper part contained air (attenuation coefficient varies from -911.8 to $-790 \mathrm{HU}$ ). Printed with permission and copyrights retained by 0.A.N. 


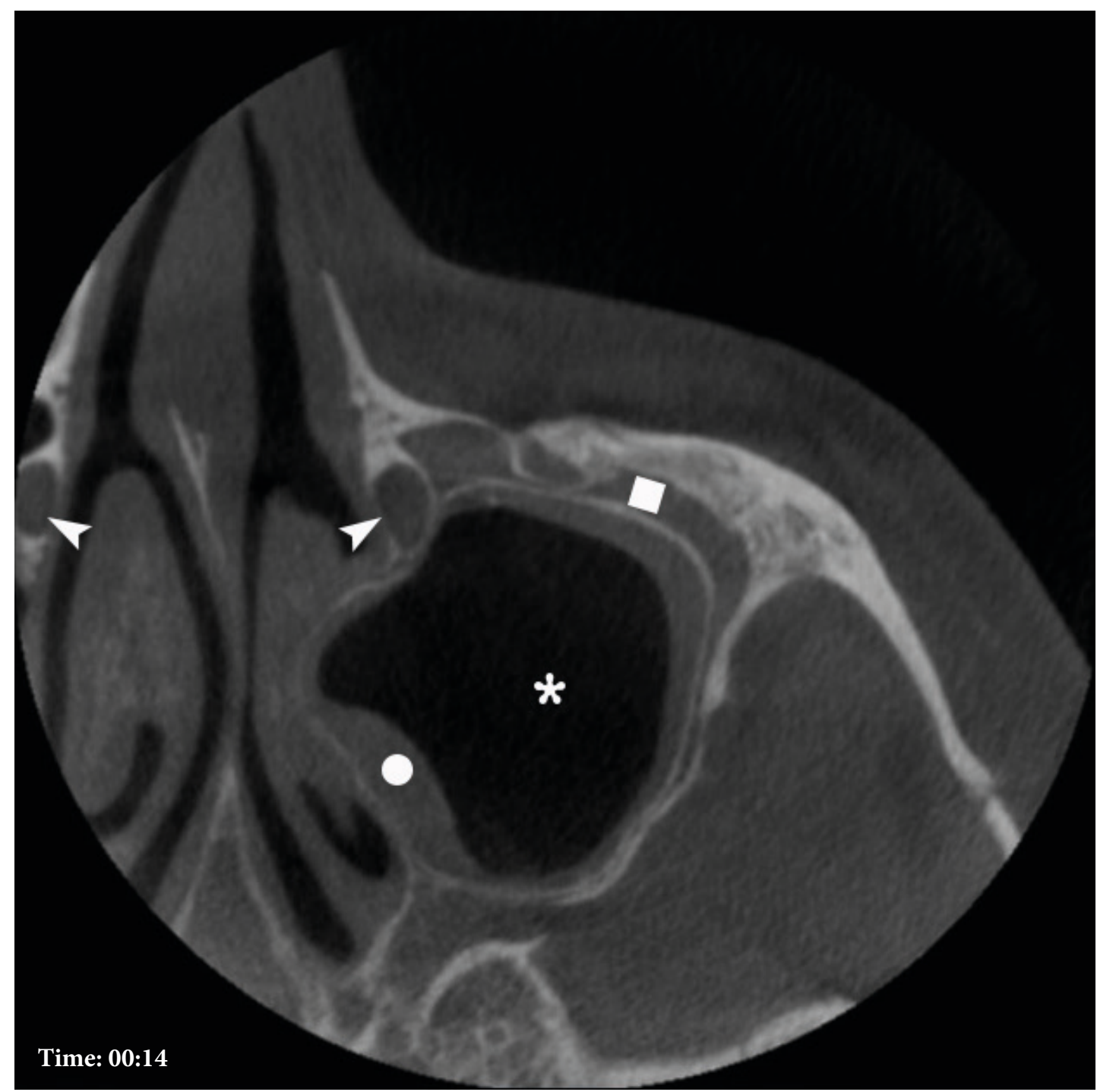

VIDEO 1. Case 1. Supplemental Video Content shows sequence of axial CBCT scans. Notes intact, opacified, oval shape nasolacrimal canals (arrowheads) measured $0.54 \times 0.31 \mathrm{~cm}$ (right) and $0.62 \times 0.35 \mathrm{~cm}$ (left). Also, a very rare feature, an intracystic air component (asterisk) without a history of previous infection or surgery, is visualized. Thickness of the cystic walls (dot) varies from 0.67 to $4.37 \mathrm{~mm}$. Quadrate labels on hyperplasia of the Schneiderian membrane.

Video is available in the page of the full-text article on dtjournal.org and in the YouTube channel, available at https://youtu. be/yigKLrEQMlw. Or just point the smartphone/tablet camera at the QR code and click on the pop-up menu "Open ... in ... ." Total video 's duration: 37 seconds.

Printed with permission and copyrights retained by O.A.N.

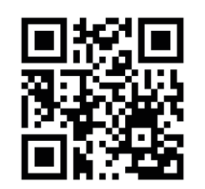

QR code leads to Video 1 at

YouTube channel Videos DTJournal 
$5 \mathrm{~mm}$ ) with the lower nasal meatus (synonyms: rhinostomy, ${ }^{14}$ inferior meatal antrostomy ${ }^{20}$ ) the sinus was properly irrigated.

Pathohistology proved the diagnosis, revealing (Fig 2C) cystic lumen, nonkeratinized stratified squamous epithelium lining measuring three to ten cells in thickness, and connective tissue capsule (synonym: connective tissue wall ${ }^{21}$ ). 1-year followup showed no data about recurrence or functional disturbances.
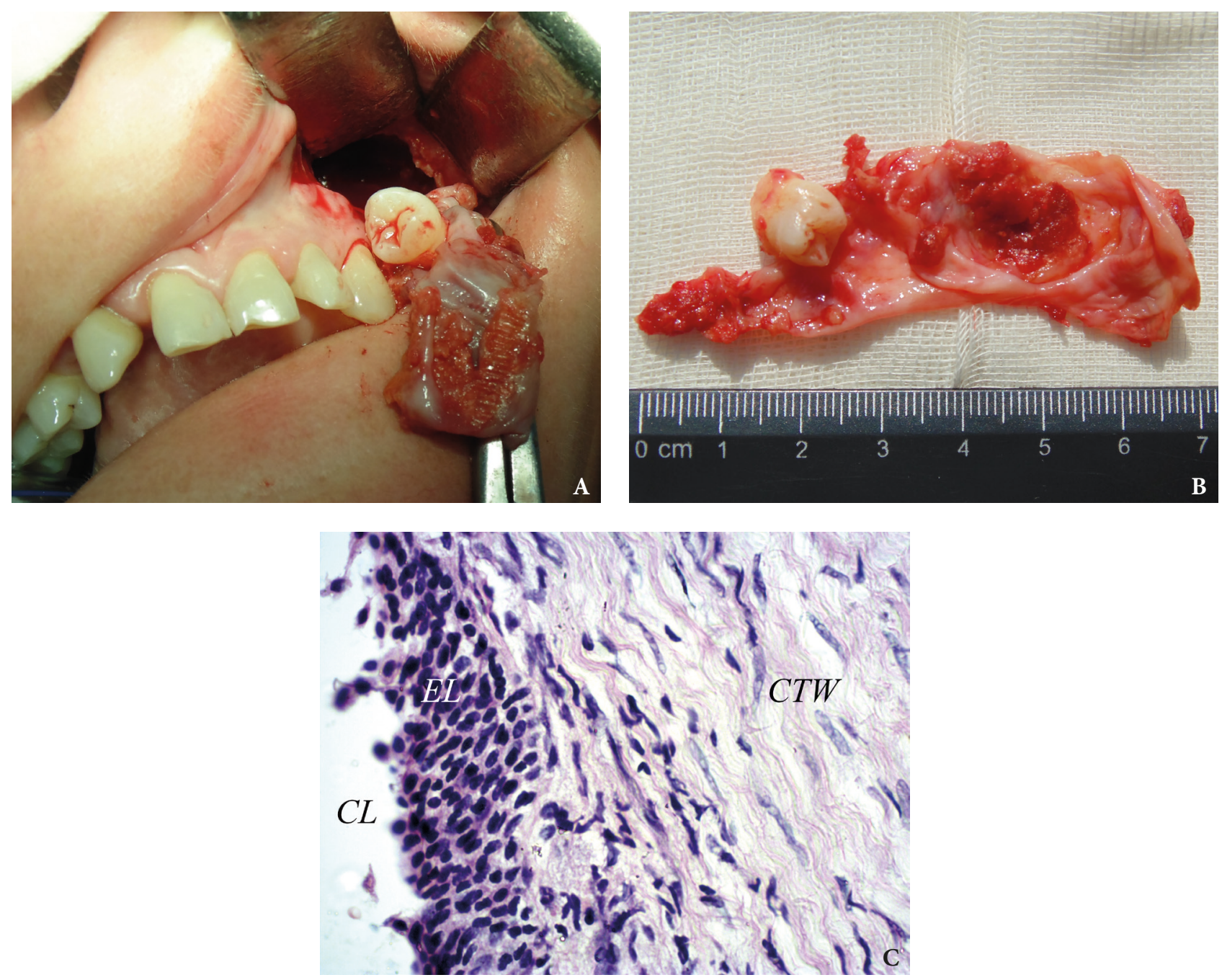

FIGURE 2. Case 1. A - intraoperative view, B - specimen after removal. Microscopic section (C) shows cystic lumen (CL), nonkeratinized stratified squamous epithelium lining (EL) measuring three to ten cells in thickness, and connective tissue wall (CTM) (hematoxylin and eosin stain; magnification $\times 40$ ). Fig 2A and B printed with permission and copyrights retained by 0.A.N. Fig 2C printed with permission and copyrights retained by V.I.Z. and P.P.S.

\section{CASE 2}

In November 2016, a 60-year-old Caucasian woman was referred by a general dentist to the Department of Oral and Maxillofacial Surgery. The two major complaints were left nasal obstruction that has lasted for about the last few years and left eye tearing (i.e., epiphora) that has been going on for the last couple of months. The patient initially consulted an ophthalmologist, but his drug prescriptions did not reduce the manifestations of tearing.

After the CBCT (Planmeca ProMax 3D Max, Planmeca, Finland) the patient was consulted by a dentist. Thickness of CT slices was $0.2 \mathrm{~mm}$. The diagnosis of giant dentigerous cyst of the left maxillary sinus was established and female was redirected to the inpatient clinic for further surgical 
treatment. The patient had no comorbidities.

Three-dimensional CBCT showed ectopic position of the upper left third molar (Fig 3). CBCT revealed a gigantic radiolucent unilocular cystic lesion measuring $4.18 \times 3.22 \mathrm{~cm}$ on coronal scans (Fig 4A) and $4.2 \times 3.94 \mathrm{~cm}$ on axial scans (Fig 4B) in the cyst's largest dimension. The cystic lesion filled the entire left maxillary sinus. The lesion's content attenuation coefficient varies from -282.1 to $-181.6 \mathrm{HU}$, which suggested that lesion contains fluid. No signs of intracystic aeration were noted.

Cyst's expansion to the level of nasal septa, its and the medial wall of the sinus deformation and displacement to the contralateral sinus direction were noted. Lateral, posterior, inferior, and superior walls of the left maxillary sinus were also expanded by the cyst outwards (Fig 5).

Analysis of axial CT scans along the entire length of the left nasolacrimal duct (from fossa of the lacrimal sac to the inferior nasal meatus) ${ }^{22}$ clearly demonstrated complete compression of the bony canal with duct at the level of its middle and lower parts (VIDEO 2) (Supplemental Video Content). An axial CT scan at the level of upper part of nasolacrimal canals demonstrated intact, opacified, ${ }^{23}$ oval shaped nasolacrimal ducts measured $0.44 \times 0.42 \mathrm{~cm}$ (right) and $0.52 \times 0.36$ (left). Scan at the level of middle part showed complete compression of the left nasolacrimal canal with duct. A right nasolacrimal duct is still intact opacified oval shaped and measured $0.7 \times 0.52 \mathrm{~cm}$. Video is available in the page of the full-text article on dtjournal.org and in the YouTube channel, available at https://youtu.be/ z5TcFup312w. Total video's duration: 45 seconds.

VIDEO 3 (Supplemental Video Content) showed that left osteomeatal complex is not recognizable due to severe obstruction and deformation by the gigantic cyst. Video is available in the page of the full-text article on dtjournal.org and in the YouTube channel, available at https://youtu.be/8LgYyjh1Tok. Total video's duration: 54 seconds.

The cystic lesion had well-defined sclerotic borders, with exception at the inferior, posterior, and lateral walls of the sinus.

The purpose of the surgery was not only to remove the giant cystic lesion with ectopic molar but also to reestablish tear flow ${ }^{3}$ inside the entire length of left nasolacrimal duct. This aim required from a surgeon (Ievgen I. Fesenko) to remove carefully not only the expanded "own" cortical bone around the cystic wall but also a lateral part of a compressed bony nasolacrimal canal. ${ }^{24}$ Because leaving of that thin bony layers will gave no possibility to decompress the left nasolacrimal duct. Also, the attention should be paid to careful enucleation of the cyst at the orbital floor level.

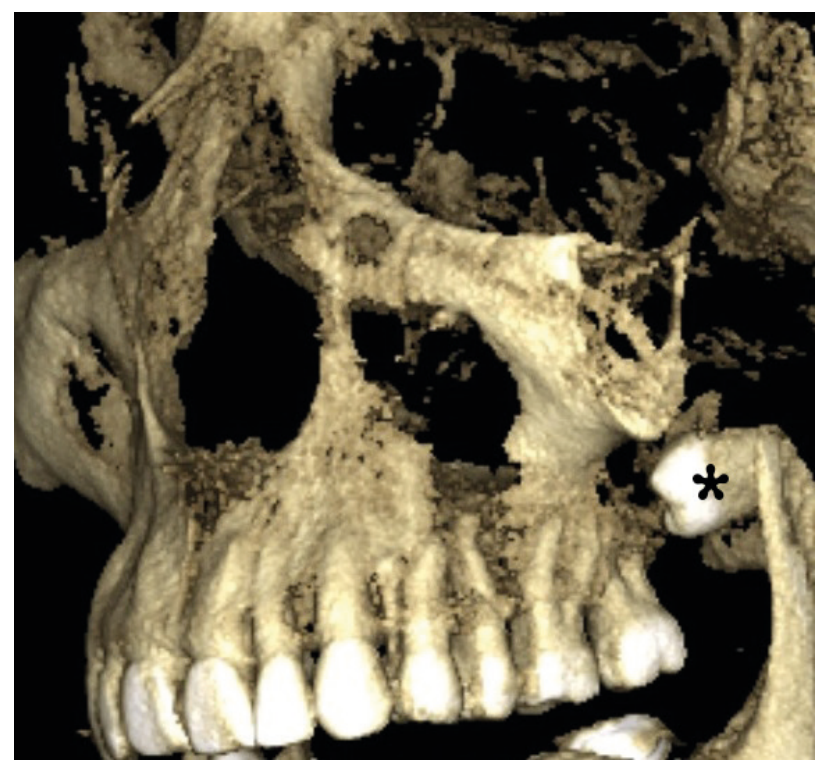

FIGURE 3. Case 2. 3-dimensional CBCT scan showed upper left third molar (asterisk) in an ectopic position at moment of examination. Printed with permission and copyrights retained by I.I.F. 

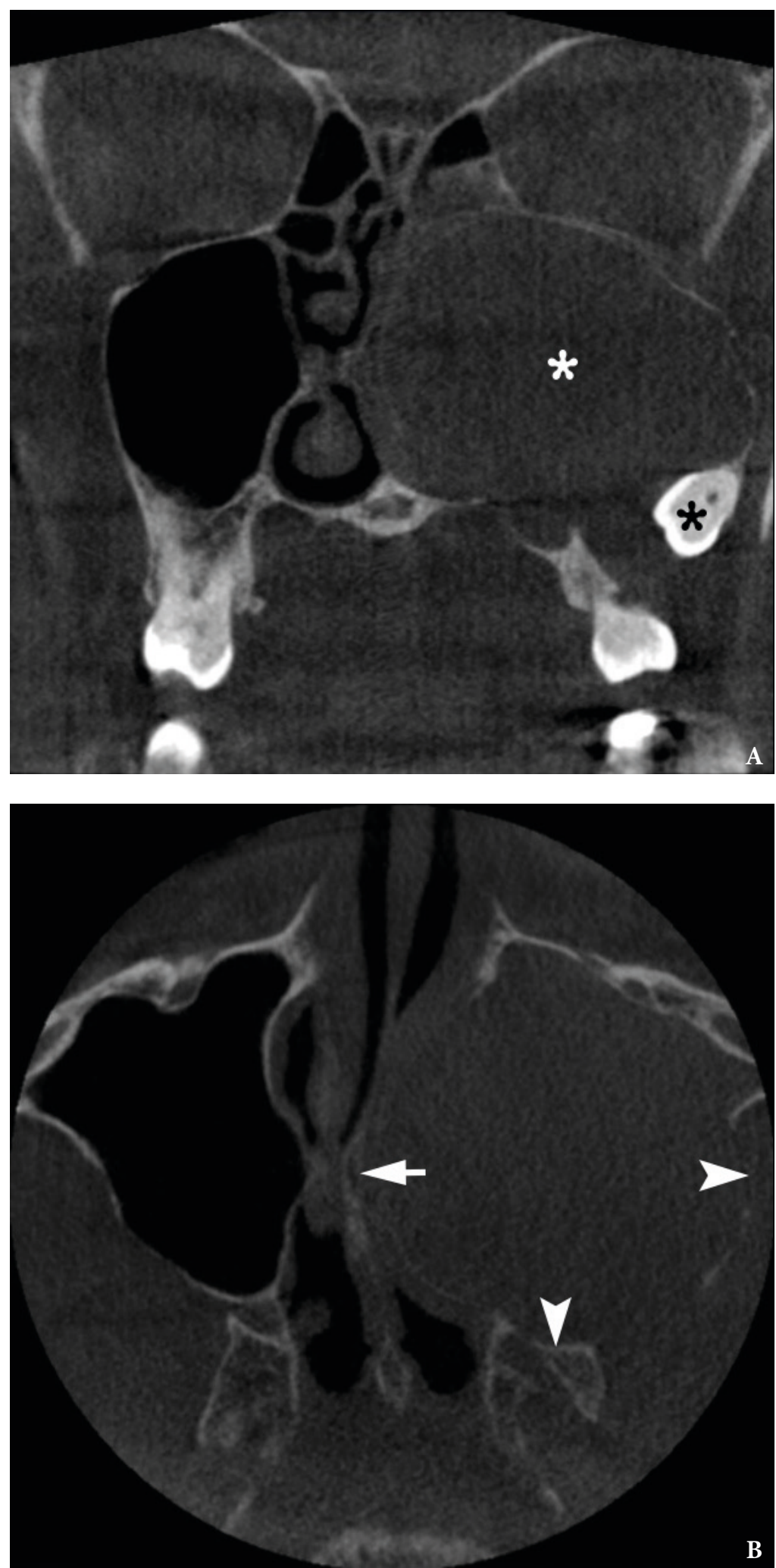

FIGURE 4. Case 2. A coronal CBCT scan (A) shows ectopic upper third molar (black asterisk) and giant dentigerous cyst (white asterisk) measuring $4.18 \times 3.22$ cm which filled entire left maxillary sinus. On axial scan (B) the lesion measured $4.2 \times 3.94 \mathrm{~cm}$ expanding to the level of nasal septum, deforming (arrow) and displacing it and the medial wall of the sinus to the contralateral sinus direction. Lateral and posterior wall of the left maxillary sinus were also expanded by cyst outwards (arrowheads). Printed with permission and copyrights retained by I.I.F. 

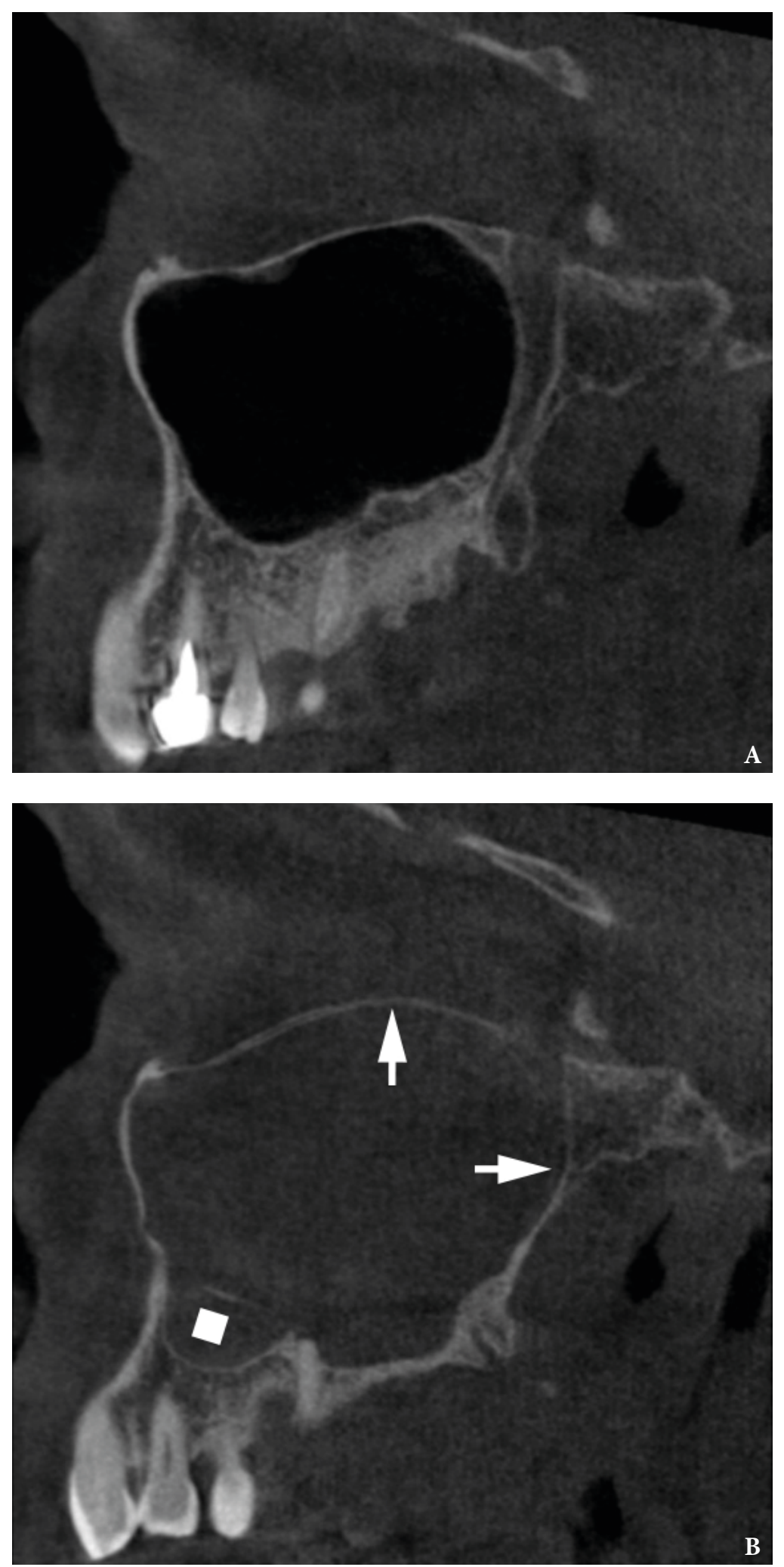

FIGURE 5. Case 2. Comparison of sagittal CBCT scans of the intact right maxillary sinus (A) and left one (B), all walls of which are expanded by a giant dentigerous cyst. Demonstrates a significant deformation (arrows) of posterior and upper wall of the left sinus causing elevation of the orbital floor. Quadrate labels thickening of the sinus mucosa. Printed with permission and copyrights retained by I.I.F. 

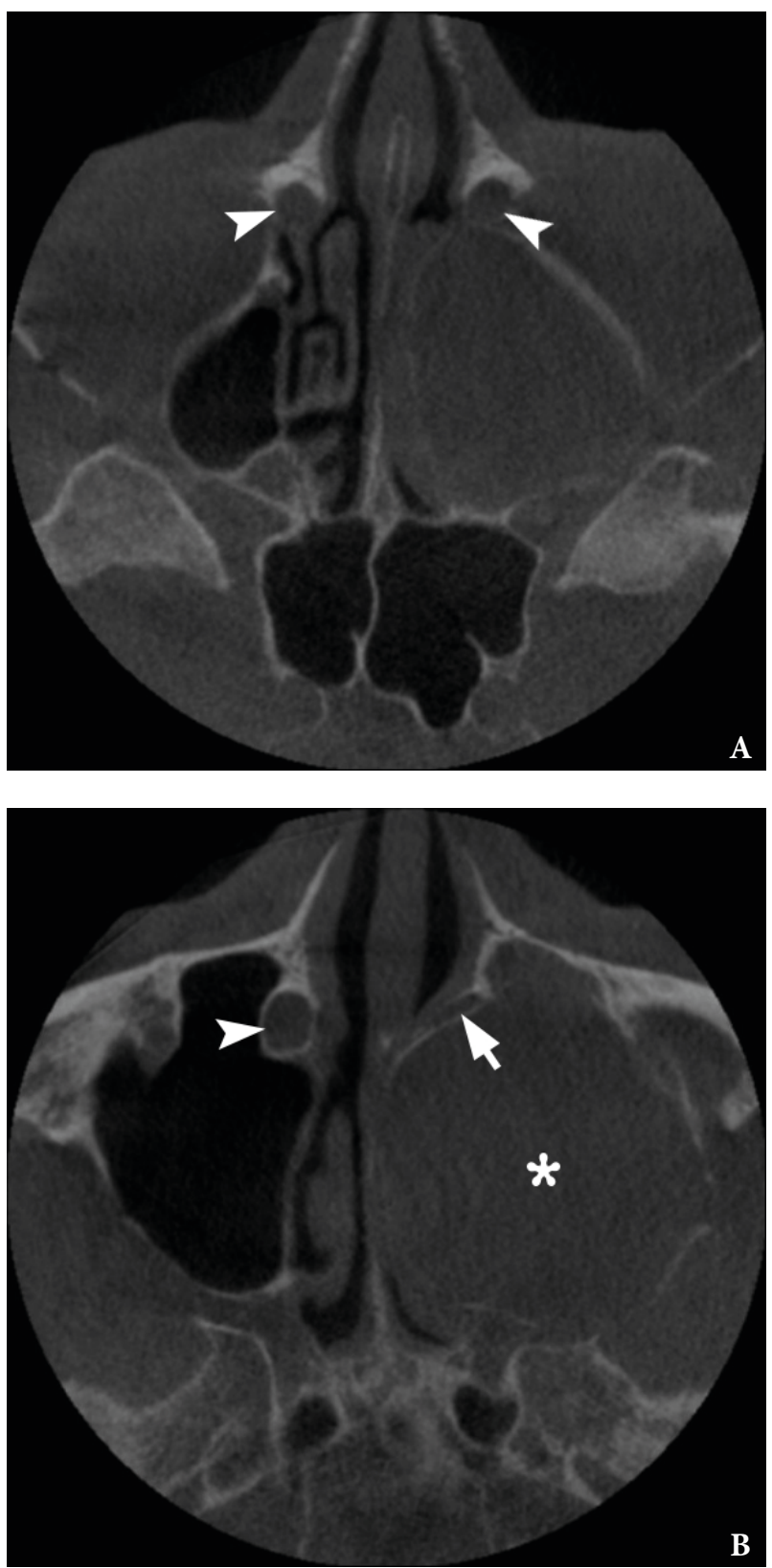

VIDEO 2. Case 2. Supplemental Video Content demonstrating axial CT scans at the level of upper part (A) of nasolacrimal canals with intact, opacified, oval shaped nasolacrimal ducts (arrowheads) measured $0.44 \times 0.42 \mathrm{~cm}$ (right) and $0.52 \times 0.36 \mathrm{~cm}$ (left). Scans at the level of middle (B) and lower parts showed complete compression of the left nasolacrimal canal with duct (arrow) by the cyst (asterisk); a right nasolacrimal duct (arrowhead) is still intact, opacified, oval shaped and measured $0.7 \times 0.52 \mathrm{~cm}$.

Video is available in the page of the full-text article on dtjournal.org and in the YouTube channel, available at https://youtu.be/25TcFup312w. Or just point the smartphone/tablet camera at the QR code and click on the pop-up menu "Open ... in .... ." Total video 's duration: 45 seconds.

Printed with permission and copyrights retained by l.I.F.

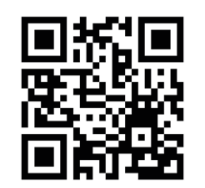

QR code leads to Video 2 at

YouTube channel Videos DTJournal 


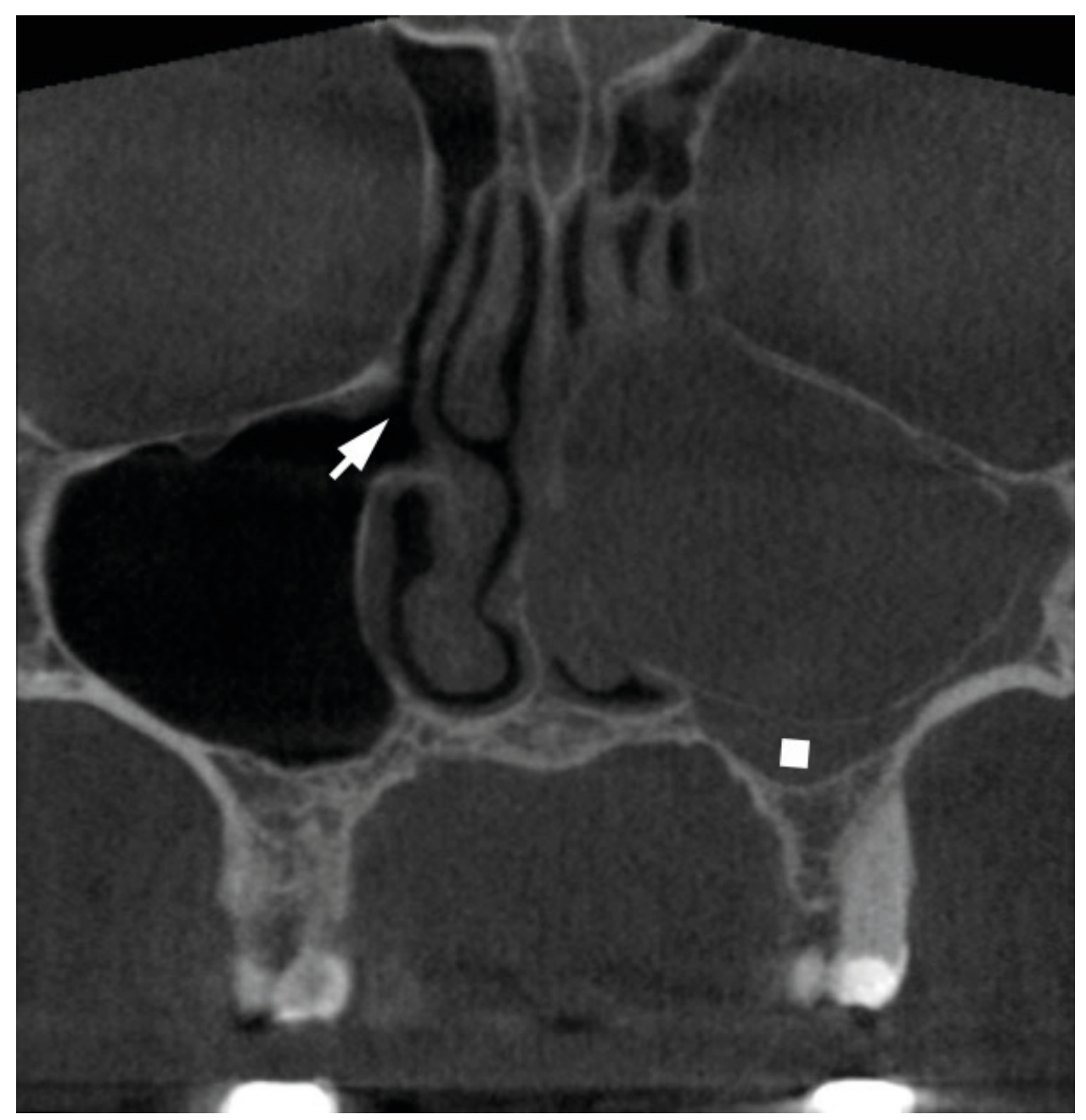

VIDEO 3. Case 2. Supplemental Video Content shows coronal CT scans. Right osteomeatal complex shows no signs of obstruction. Right maxillary sinus ostium is labeled by arrow. Left osteomeatal complex is not recognizable due to severe obstruction and deformation by a gigantic cyst. Thickening of Schneiderian membrane labeled by quadrate.

Video is available in the page of the full-text article on dtjournal.org and in the YouTube channel, available at https://youtu.be/8LgYyjh1Tok. Or just point the smartphone/tablet camera at the QR code and click on the pop-up menu "Open ... in .... ." Total video 's duration: 54 seconds.

Printed with permission and copyrights retained by I.I.F.

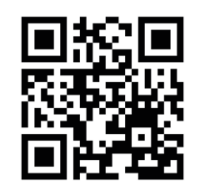

QR code leads to Video 3 at

YouTube channel Videos DTJournal 
Additionally, the CT proved the compression of the left greater palatal canal by a cyst what made impossible to use that route for maxillary nerve block (synonym: palatine route of pterygopalatine anesthesia ${ }^{25}$ during the surgery.

A surgery was done under local anesthesia (maxillary nerve block using tuberal route, infraorbitalnerveblock, and infiltration anesthesia) and sedation. Caldwell-Luc approach was created at the anterolateral wall of the maxillary sinus after performing combined incision, horizontal vestibular anteriorly and crestal posteriorly. Avoiding ectopic molar migration, it was removed in a first stage. And the cyst with expanded cortical bone was removed in a second stage (Fig 6). Brown color liquid flowed out of the cystic cavity and was aspirated. Histopathological report confirmed the diagnosis of dentigerous cyst. The recovery period was uncomplicated. Two weeks after surgery the patient noted no signs of left eye epiphora.

Comparison of the dentigerous cysts in patient 1 and 2 is highlighted in the Table 1.

\section{DISCUSSION}

Osteomeatal complex (synonym: ostiomeatal complex $)^{26}$ obstruction is a common complication of different pathologic conditions in maxillary sinus. After scrupulous analysis of English literature, the combination of nasolacrimal duct and osteomeatal complex obstructions due to gigantic dentigerous cyst was found in 5 studies (Table 2) with 6 cases. $^{8-12}$ But in none of those cases a dentigerous cyst associated with upper impacted/ectopic third molar was presented. Study of Emanuelli et $\mathrm{a}^{27}$ is also more than worth of attention. Despite the fact that CT data in their case shows giant dentigerous cyst of the maxillary sinus associated with ectopic upper third molar there was no mentions about epiphora or CT signs of the nasolacrimal duct obstruction. ${ }^{27}$

Case 1 and 2 clearly support the opinion of Salman that coronal CT scans are the best to visualize and assess the osteomeatal complex and its obstruction/narrowing by the lesions. ${ }^{20}$ But for the verification of nasolacrimal duct

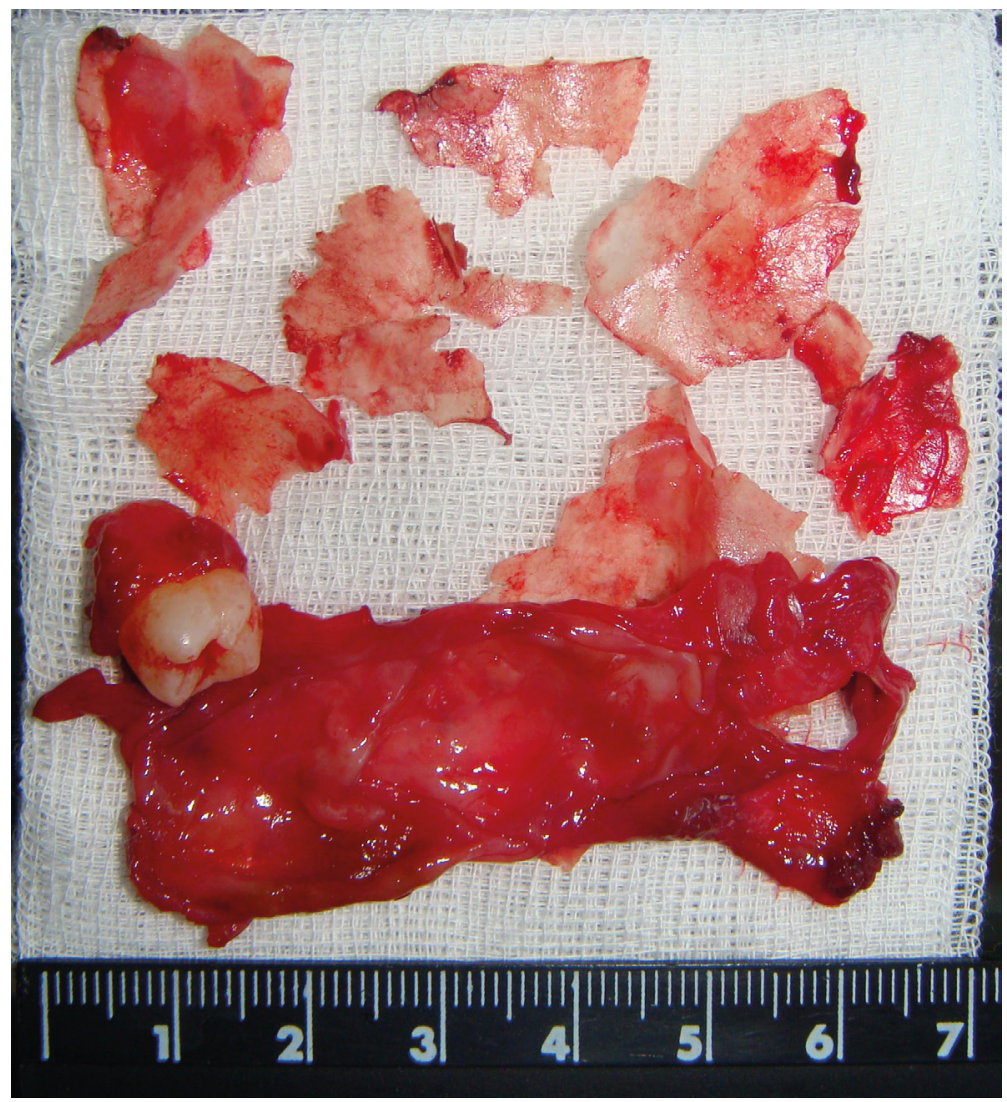

FIGURE 6. Case 2. Specimen of the cyst, ectopic tooth, and the bony fragments after removal. Printed with permission and copyrights retained by I.I.F. 
TABLE 1. Comparison of Patient 1 and 2 with the Giant Dentigerous Cysts of the Maxillary Sinus.

\begin{tabular}{|c|c|c|}
\hline Features & Case 1 & Case 2 \\
\hline Patient's age/gender & $44 / \mathrm{F}$ & $60 / \mathrm{F}$ \\
\hline Associated tooth & Impacted upper left third molar & Ectopic upper left third molar \\
\hline Epiphora & No & Yes \\
\hline Headaches & Yes & No \\
\hline Chronic nasal obstruction & Yes & Yes \\
\hline Size of the cyst in the cyst's largest dimension on axial CT scans & $2.8 \times 2.9 \mathrm{~cm}$ & $4.2 \times 3.94 \mathrm{~cm}$ \\
\hline Size of the cyst in the cyst's largest dimension on coronal CT scans & $2.82 \times 3.15 \mathrm{~cm}$ & $4.18 \times 3.22 \mathrm{~cm}$ \\
\hline Maximal thickness of the sinus membrane & $4.52 \mathrm{~mm}$ & $7.64 \mathrm{~mm}$ \\
\hline $\begin{array}{l}\text { Does thickened mucosa fill the entire space between the sinus } \\
\text { walls and the sclerotic border of the cyst? }\end{array}$ & Yes & Yes \\
\hline Osteomeatal complex obstruction & Yes & Yes \\
\hline Appearance of nasolacrimal ducts at CT & Opacified & Opacified \\
\hline Nasolacrimal duct obstruction & No & Yes \\
\hline Presence of intracystic air-fluid level or partial aeration & Air-fluid level & No \\
\hline Thickness of the cystic walls & Varies from 0.67 to $4.37 \mathrm{~mm}$. & The cyst wall was not defined \\
\hline $\begin{array}{l}\text { Variation of attenuation coefficient of the cystic wall, } \\
\text { Hounsfield units (HU) }\end{array}$ & From -165.1 to $32.74 \mathrm{HU}$ & The cyst wall was not defined \\
\hline $\begin{array}{l}\text { Variation of attenuation coefficient of the intracystic fluid } \\
\text { component, Hounsfield units (HU) }\end{array}$ & From -195.2 to $-20.4 \mathrm{HU}$ & From -282.1 to $-181.6 \mathrm{HU}$ \\
\hline $\begin{array}{l}\text { Variation of attenuation coefficient of the intracystic air } \\
\text { component, Hounsfield units (HU) }\end{array}$ & From -911.8 to $-790 \mathrm{HU}$ & No CT signs of the air component \\
\hline
\end{tabular}

TABLE 2. Articles Describing the Nasolacrimal Duct Obstruction Due to Compression by Dentigerous Cyst.

\begin{tabular}{|c|c|c|c|c|c|}
\hline$\#$ & $\begin{array}{c}\text { Tooth`s Crown Associated } \\
\text { with Cyst }\end{array}$ & $\begin{array}{c}\text { Clinical/ } \\
\text { Radiological Signs of } \\
\text { Osteomeatal Complex } \\
\text { Obstruction }\end{array}$ & $\begin{array}{l}\text { No. of } \\
\text { Patients }\end{array}$ & $\begin{array}{l}\text { Age }(y r) / \\
\text { Gender }\end{array}$ & Year of Publication and Title of the Article \\
\hline 1 & Ectopic right canine & Yes & 1 & $41 / \mathrm{M}$ & $\begin{array}{l}\text { (1997) A case of a large dentigerous cyst } \\
\text { containing a canine tooth in the maxillary } \\
\text { antrum leading to epiphora. }\end{array}$ \\
\hline \multirow{2}{*}{2} & Ectopic right deciduous canine & Yes & 1 & $3 / \mathrm{F}$ & \multirow{2}{*}{$\begin{array}{l}\text { (2000) Nasolacrimal duct obstruction secondary } \\
\text { to ectopic teeth. }\end{array}$} \\
\hline & Right canine & Yes & 1 & $32 / \mathrm{F}$ & \\
\hline 3 & $\begin{array}{l}\text { The tooth`s number was not } \\
\text { indicated by the authors }\end{array}$ & Yes & 1 & $23 / \mathrm{M}$ & $\begin{array}{l}\text { (2003) Dentigerous cyst in the maxillary sinus: A } \\
\text { rare cause of nasolacrimal obstruction. } .^{10}\end{array}$ \\
\hline 4 & Supernumerary tooth & Yes & 1 & $11 / \mathrm{M}$ & $\begin{array}{l}\text { (2009) A rare cause of nasolacrimal duct obstruction: } \\
\text { dentigerous cyst in the maxillary sinus. }{ }^{11}\end{array}$ \\
\hline 5 & Right canine & Yes & 1 & $21 / \mathrm{M}$ & $\begin{array}{l}\text { (2012) A case of an extensive dentigerous cyst in } \\
\text { the maxillary sinus leading to epiphora and nasal } \\
\text { obstruction. }{ }^{12}\end{array}$ \\
\hline 6 & Ectopic upper left third molar & Yes & 1 & $60 / \mathrm{F}$ & $\begin{array}{l}\text { (2020) Case } 2 \text { in our study "Gigantic dentigerous } \\
\text { cysts associated with the ectopic/impacted upper } \\
\text { third molars: Computed tomography analysis } \\
\text { of nasolacrimal duct and osteomeatal complex } \\
\text { obstructions and review of literature." }\end{array}$ \\
\hline
\end{tabular}


obstruction, among coronal and axial CT scans, according to cases 1 and 2, the axial ones are the most informative due to the oblique anatomy of the duct. Nasolacrimal duct (NLD) (synonym: lacrimal duct) ${ }^{19}$ is a bilateral tube-shape structure inside the nasolacrimal canal, which passes from lacrimal fossa down and opens in inferior nasal meatus. Along the canals ' passage they are neighboring with maxillary sinuses (synonym: Highmore's antrums $)^{28}$ and are separated from it by just a very thin layer of bone $(\sim 0.67 \mathrm{~mm}$ in case 1 and $\sim 0.79 \mathrm{~mm}$ in case 2).

The data analysis by Czyz et $\mathrm{al}^{23}$ revealed that patient's position affects the appearance of nasolacrimal duct at CT. In 70 percent of CT investigations the NLD is opacified and in $30 \%$ of cases is aerated (fully/partially). ${ }^{23}$ Also, in every particular patient the NLD can be opacified and aerated from different sides. ${ }^{23}$ In case 1 and 2 the patient was in an upright position upon CBCT. In both cases nasolacrimal ducts were opacified. The fact that left eye epiphora disappeared two weeks after surgery indicates that surgical technique focused on decompression of the NLD proved its effectiveness and can be recommended in similar cases.

Discussing ectopic position of the wisdom tooth in patient 2 we support the opinion of Sivolella et $\mathrm{al}^{17}$ that "when dentigerous cysts surround impacted teeth, they often displace the teeth into ectopic positions; ectopic teeth in the maxilla may be displaced into the maxillary sinus." Firstly, because we can hypothesize that the left wisdom tooth in case 2 initially was in impacted position and after cyst's growth it became an ectopic tooth. Secondly, its ectopic position in the maxillary sinus is explained by the cystic growth to the gigantic size in the maxillary antrum.

Presence of intracystic air-fluid level in case 1 is completely unusual and very unique feature for the dentigerous cysts. Intrasinus air-fluid level is a common sign for: 1) acute purulent sinusitis and position of air-fluid level in the sinus depends on the patient's position (vertical or horizontal) ${ }^{14,29}$ and 2) blood after trauma or in patients with bleeding disorders ${ }^{30}$. On CT images the collected blood is denser than inflammatory exudate or mucosal edema. ${ }^{31}$ İmamoğlu et $\mathrm{al}^{32}$ presented intracystic air densities suggesting infection within the dentigerous cyst. In their case the air is visualized as small solitary inclusions within fluid content and with no signs of air-fluid level. ${ }^{31}$

Sclerotic well-defined borders of the cysts were noted on CT in both our cases but in areas of close contact between walls ${ }^{33}$ of the maxillary sinus and sclerotic bony border of the cyst they were undistinguished due to their compression. Contrast enhancement can be seen in the cyst wall only upon contrast enhanced multi-slice CT. ${ }^{34}$ In the study of Zerrin et $\mathrm{al}^{35}$, cyst wall contrast was seen in 5 of the 9 cases. In our cases cyst's walls are visualized on CT images in upper portion of the cyst only in case 1 due to the significant intracystic aeration. In middle and lower cyst's portion of case 1 the walls were similarly undistinguished as in the entire cyst of case 2.

Mucosal lining of maxillary sinus is considered to be normal when is less than $4 \mathrm{~mm} .{ }^{29}$ It 's notable that in both cases (1 and 2) thickened mucosa filled the entire space between the sinus walls and the sclerotic border of the cysts. In case 1 maximal thickness of the Schneiderian membrane reached $4.52 \mathrm{~mm}$ and in case 2 - reached $7.64 \mathrm{~mm}$ without even minimal signs of intrasinus aeration.

Reported case of squamous cell carcinoma arisen in a mandibular dentigerous cyst in 72-year-old male ${ }^{21}$ evidenced us for a need to remove the dentigerous cysts as soon as possible avoiding not only the functional disturbances in the area of maxillary sinus but also a possible malignization. That is why we must carefully select a cyst marsupialization, as one of the internationally proposed types of surgery, in a very limited amount of cases. Caldwell-Luc operation is still one of the leading types of surgery in case of giant follicular cysts of the sinus. The endoscopicassisted removal of the cyst and associated tooth has not only a variety of modifications $s^{27,36,37}$ but also its performance has some limitations. Case of Emanuelli et $\mathrm{al}^{27}$ showed that it can be problematic, during the endoscopic surgery, to remove lateral sclerotic wall of the cyst. Two cases of Bernardi et $\mathrm{al}^{38}$ successfully implemented both microscopic and endoscopic support for the traditional Caldwell-Luc surgery.

Thus, cystic expansion into the nasal cavity, the pterygo-maxillary area, the ethmoidal and the orbital regions can cause morphological, functional, nervous and inflammatory complications. ${ }^{38}$ Among 6 published cases with nasolacrimal duct 
obstruction caused by dentigerous cysts, in 4 cases the cysts originated from canines, in one case was not established the tooth number which was turned by the crown into the cavity of the cyst, and in another one the dentigerous cyst has arisen around the supernumerary tooth. ${ }^{8-12}$ In contrast to the cysts on the mandible where they grow mesiodistally, ${ }^{39}$ on the maxilla they easily prolapsed into maxillary sinus where they can asymptomatically reach gigantic sizes. Similarly to other studies focused on unique CT characteristics of jaw cysts, ${ }^{40}$ in our cases the CBCT also proved its effectiveness in diagnosis and planning of the surgeries.

\section{CONCLUSIONS}

Summarizing, our first case represents a unique CT appearance of intracystic air-fluid level which is completely unusual for dentigerous cyst. Second case describes a first ever reported case of permanent acquired nasolacrimal duct obstruction due to compression by gigantic dentigerous cyst associated with upper third molar in an ectopic position at the moment of preoperative CT. Despite the fact that in both cases osteomeatal complex obstruction complicated the situations, the removal (with compressed lateral wall of the NLD) of giant lesions of the maxillary sinus via classic Caldwell-Luc approach allowed as well to resolve all functional disturbances successfully.

\section{ROLE OF CO-AUTHORS}

Tetiana M. Babkina (editing).

Oleg G. Shekera (editing).

Yulia O. Storozhchuk (writing and editing).

Kyrylo I. Telukha (editing).

Oleksandr A. Nozhenko (concept of the article, material collection, writing, and editing).

Ievgen I. Fesenko (material collection and writing).

Valentyna I. Zaritska (material collection and writing).

Pavlo P. Snisarevskyi (material collection).

All authors read and approved the final manuscript.

\section{TERM OF CONSENT}

No needed.

\section{FUNDINGS}

No funding was received for this study.

\section{ACKNOWLEDGMENTS}

None.

\section{REFERENCES}

1. Shen GL,NgJD, MaXP.Etiology, diagnosis, management and outcomes of epiphora referrals to an oculoplastic practice. Int J Ophthalmol 2016;9(12):1751-5. https:// doi.org/10.18240/ijo.2016.12.08.

2. Yazici B, Hammad AM, Meyer DR. Lacrimal sac dacryoliths: predictive factors and clinical characteristics. Ophthalmology 2001;108(7):1308-12. https://doi.org/10.1016/s0161-6420(01)00596-6.

3. Kang JM, Kalin-Hajdu E, Idowu OO, Vagefi MR, Kersten RC. Nasolacrimal obstruction following the placement of maxillofacial hardware. Craniomaxillofac Trauma Reconstr 2020;13(1):32-7. https://doi.org/10.1177/1943387520906004.

4. Ali MJ, Gupta H, Honavar SG, Naik MN. Acquired nasolacrimal duct obstructions secondary to nasoorbito-ethmoidal fractures: patterns and outcomes. Ophthalmic Plast Reconstr Surg 2012;28(4):242-45. https://doi.org/10.1097/IOP.0b013e31823f3266.

5. Glatt HJ, Chan AC. Lacrimal obstruction after medial maxillectomy. Ophthalmic Surg 1991;22(12):757-8.

6. Liang BCC, Chau Y, Lam DSC, Chan NR. Undifferentiated sinonasal carcinoma with nasolacrimal duct obstruction. Arch Ophthalmol 2004;122(2):290-3. https://doi.org/10.1001/archopht.122.2.290.

7. Baer ST, Drysdale A, Moore-Gillon V. Giant radicular cyst in the maxillary antrum presenting with chronic epiphora. J Laryngol Otol 1988;102(4):365-7.

8. Altas E, Karasen RM, Yilmaz AB, Aktan B, Kocer I, Erman $Z$. A case of a large dentigerous cyst containing a canine tooth in the maxillary antrum leading to epiphora. J Laryngol Otol 1997;111:641-3.

9. Alexandrakis G, Hubbell RN, Aitken PA. Nasolacrimal duct obstruction secondary to ectopic teeth. Ophthalmology 2000;107:189e-92e.

10. Bajaj MS, Mahindrakar A, PushkerN, Balasubramanya R. Dentigerous cyst in the maxillary sinus: a rare cause of nasolacrimal obstruction. Orbit 2003;22(4):28992. https://doi.org/10.1076/orbi.22.4.289.17241.

11. Ray B, Bandyopadhyay SN, Das D, Adhikary B. A rare cause of nasolacrimal duct obstruction: dentigerous cyst in the maxillary sinus. Indian J Ophthalmol 2009;57(6):4657. https://doi.org/10.4103/0301-4738.57161.

12. Akyol UK, Salman IA. A case of an extensive dentigerous cyst in the maxillary sinus leading to epiphora and 
nasal obstruction. J Emerg Med 2012;43(6):1004-7. https://doi.org/10.1016/j.jemermed.2010.11.045.

13. Giordano Resti A, Bertazzoni G, Trimarchi M. Nasolacrimal duct obstruction secondary to dental impaction. Eur J Ophthalmol 2014;24(4):611-3. https://doi.org/10.5301/ejo.5000410.

14. Tymofieiev OO. Manual of maxillofacial and oral surgery [Russian]. 5th ed. Kyiv: Chervona Ruta-Turs; 2012.

15. Jones AV, Craig GT, Franklin CD. Range and demographics of odontogenic cysts diagnosed in a UK population over a 30-year period. J Oral Pathol Med 2006;35(8):500-7. https://doi.org/10.1111/ j.1600-0714.2006.00455.x.

16. Paget J. Dentigerous cysts. Lectures on tumours. Vol. 2. London: Wilson and Ogilvy; 1853.

17. Sivolella S, Ricci S, Busca M, Stellini E, Valente M. Maxillary dentigerous cyst and ectopic third molar. Oral Surg 2014;7(S1):72-8. https://doi.org/10.1111/ ors.12111.

18. Sharma S, Chauhan JS. Bilateral ectopic third molars in maxillary sinus associated with dentigerous cyst-a rare case report. Int J Surg Case Rep 2019;61:298-301. https://doi.org/10.1016/j.ijscr.2019.07.072.

19. Shin DE. Anatomical variations from the point of view of the periodontist. In: Iwanaga J, Tubbs SR, editors. Anatomical variations in clinical dentistry. 1st ed. Cham: Springer International Publishing; 2019. https://doi.org/10.1007/978-3-319-97961-8.

20. Salman SD. The abnormal ostiomeatal complex and sinusitis. Am J Rhinol 1992;6(1):29-32. https://doi. org/10.2500/105065892781976763.

21. Maxymiw WG, Wood RE. Carcinoma arising in a dentigerous cyst: a case report and review of the literature. J Oral Maxillofac Surg 1991;49(6):639-43. https://doi.org/10.1016/0278-2391(91)90347-o.

22. Groell R, Schaffler GJ, Uggowitzer M, Szolar DH, Muellner K. CT-anatomy of the nasolacrimal sac and duct. Surg Radiol Anat 1997;19:189-91. https://doi. org/10.1007/BF01627974.

23. Czyz CN, Bacon TS, Stacey AW, Cahill EN, Costin BR, Karanfilov BI, Cahill KV. Nasolacrimal system aeration on computed tomographic imaging: effects of patient positioning and scan orientation. Clin Ophthalmol 2015;9:469-73. https://doi.org/10.2147/ OPTH.S80752.

24. Lee H, Ha S, Lee Y, Park M, Baek S. Anatomical and morphometric study of the bony nasolacrimal canal using computed tomography. Ophthalmologica 2012;227(3):153-9. https://doi.org/10.1159/000331986.

25. Tymofieiev OO, Fesenko II. Anesthesia in oral and maxillofacial surgery. 1st ed. Kyiv: OMF Publishing; 2016

26. Jude R, Horowitz J, Loree T. Ectopic molars that cause osteomeatal complex obstruction. J Am Dent Assoc
1995;126(12):1655-7. https://doi.org/10.14219/jada. archive.1995.0114.

27. Emanuelli E, Borsetto D, Brunelloc G, Sivolella S. Endoscopy-assisted removal through combined lower and middle meatotomies of an ectopic upper third molar in the sinus associated with a dentigerous cyst. Oral Maxillofac Surg Cases 2018;4(1):23-31. https://doi.org/10.1016/j.omsc.2018.02.001.

28. Mavrodi A, Paraskevas G. Evolution of the paranasal sinuses' anatomy through the ages. Anat Cell Biol 2013;46(4):235-8. https://doi.org/10.5115/ acb.2013.46.4.235.

29. Eggesbø HB. Radiological imaging of inflammatory lesions in the nasal cavity and paranasal sinuses. Eur Radiol 2006;16(4):872-88. https://doi.org/10.1007/ s00330-005-0068-2.

30. Dym RJ, Masri D, Shifteh K. Imaging of the paranasal sinuses. Oral Maxillofac Surg Clin North Am 2012;24(2):175-89. https://doi.org/10.1016/j. coms.2012.01.004.

31. Barnes L. Surgical pathology of the head and neck. Vol. 1. 2nd ed. New York: CRC Press; 2000.

32. İmamoğlu Ç, Uzel AT, İbrahim İG, Ali İM. Computed tomography findings of a dentigerous cyst associated with an ectopic tooth in the maxillary sinus. Acta Oncologica Turcica 2019;52(3):491-4. https://doi. org/10.5505/aot.2019.27676.

33. Misch CE. The maxillary sinus lift and sinus graft surgery. In: Misch CE, ed. Implant Dentistry. 2nd ed. St Louis: CV Mosby Co; 1999:469-470.

34. Koenig LJ. Diagnostic imaging: oral and maxillofacial. Vol. 2. 1st ed. Altona: Amirsys; 2011.

35. Zerrin E, Husniye DK, Peruze C. Dentigerous cysts of the jaws: Clinical and radiological findings of 18 cases. J Oral Maxillofac Radiol 2014;2(3):77-81.

36. Hasbini AS, Hadi U, Ghafari J. Endoscopic removal of an ectopic third molar obstructing the osteomeatal complex. Ear Nose Throat J 2001;80(9):667-70.

37. Wardani RS, Lekatompessy M, Senior BA. Modified transnasal endoscopic medial maxillectomy with inferior turbinate flap for dentigerous cyst. Oto Rhino Laryngol Indones 2015;45(2):151e-9e. https://doi. org/10.32637/orli.v45i2.119.

38. Bernardi S, Scarsella S, Fabio DD, Oliva A, Girolamo MD, Continenza MA, Cutilli T. Giant follicular cysts extended in pterygo-maxillary fossa, antronaso-ethmoidal and orbital space associated to exophtalmos and diplopia in young patients. Oral Maxillofacial Surg Cases 2018;4(1):17e-22e. https:// doi.org/10.1016/j.omsc.2018.02.002.

39. Lee JH, Kim SM, Kim HJ, Jeon KJ, Park KH, Huh JK. Characteristics of bony changes and tooth displacement in the mandibular cystic lesion involving the impacted third molar. $J$ Korean Assoc Oral Maxillofac Surg 2014;40(5):225-32. https://doi. 
org/10.5125/jkaoms.2014.40.5.225.

40. Nozhenko OA, Zaritska VI, Snisarevskyi PP, Fesenko II. Case report: multilocular type of mandibular simple bone cyst. Part 1: cone beam computed tomography (CBCT) findings, revision of the synonyms and treatment strategies. J Diagn Treat Oral Maxillofac Pathol 2018;2(4):179-85. https://doi. org/10.23999/j.dtomp.2018.4.6. 
Journal of Diagnostics and Treatment of Oral and Maxillofacial Pathology | DTJournal.org | ISSN 2522-1965

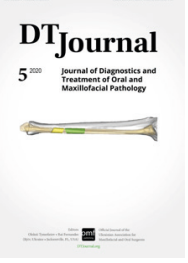

Images in Oral and Maxillofacial Surgery

Camilo Mosquera, DDS, Editor

\section{Post-Traumatic Facial and Intracranial Emphysema}

Tetiana 0. Shamova \& Ruslan A. Pavlenko

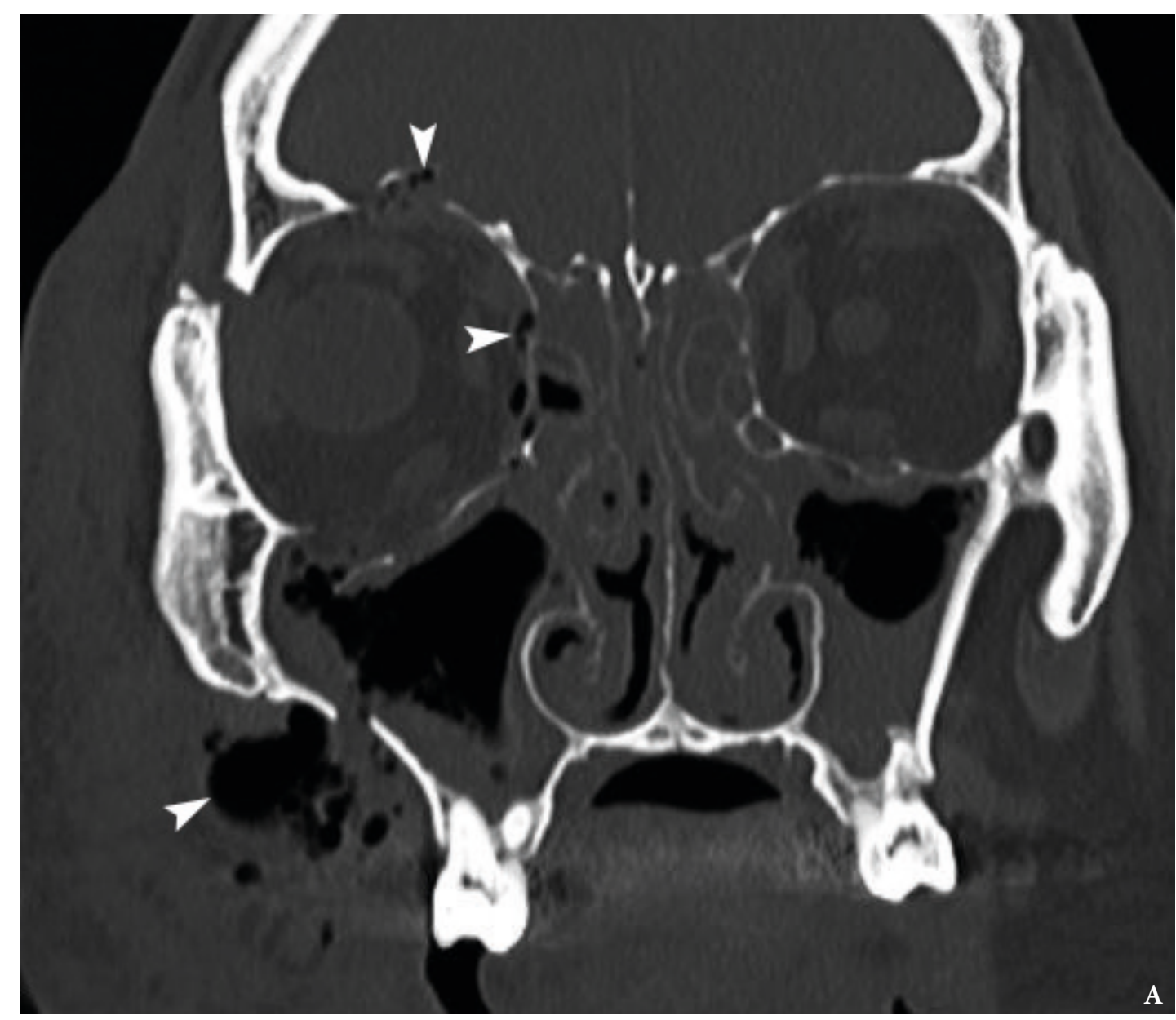

Kyiv, Ukraine

${ }^{a}$ Radiologist, Medical Center Asklepiy (place of work at moment of material collection)

shamovatatyana@gmail.com

${ }^{b}$ Oral Surgeon, Head of the Department, Center of Maxillofacial Surgery and Dentistry, Kyiv Regional Clinical Hospital.

pavlenkoruslankokl@gmail.com
How to cite this article: Shamova TO, Pavlenko RA. Post-traumatic facial and intracranial emphysema. J Diagn Treat Oral Maxillofac Pathol 2020;4(5):95-6.

Paper received 15 April 2020

Accepted 9 May 2020

Available online 29 May 2020

https://dx.doi.org/10.23999/j.dtomp.2020.5.2

(C) 2020 OMF Publishing, LLC. This is an open access article under the CC BY license (http://creativecommons.org/licenses/by-nc/4.0/) 


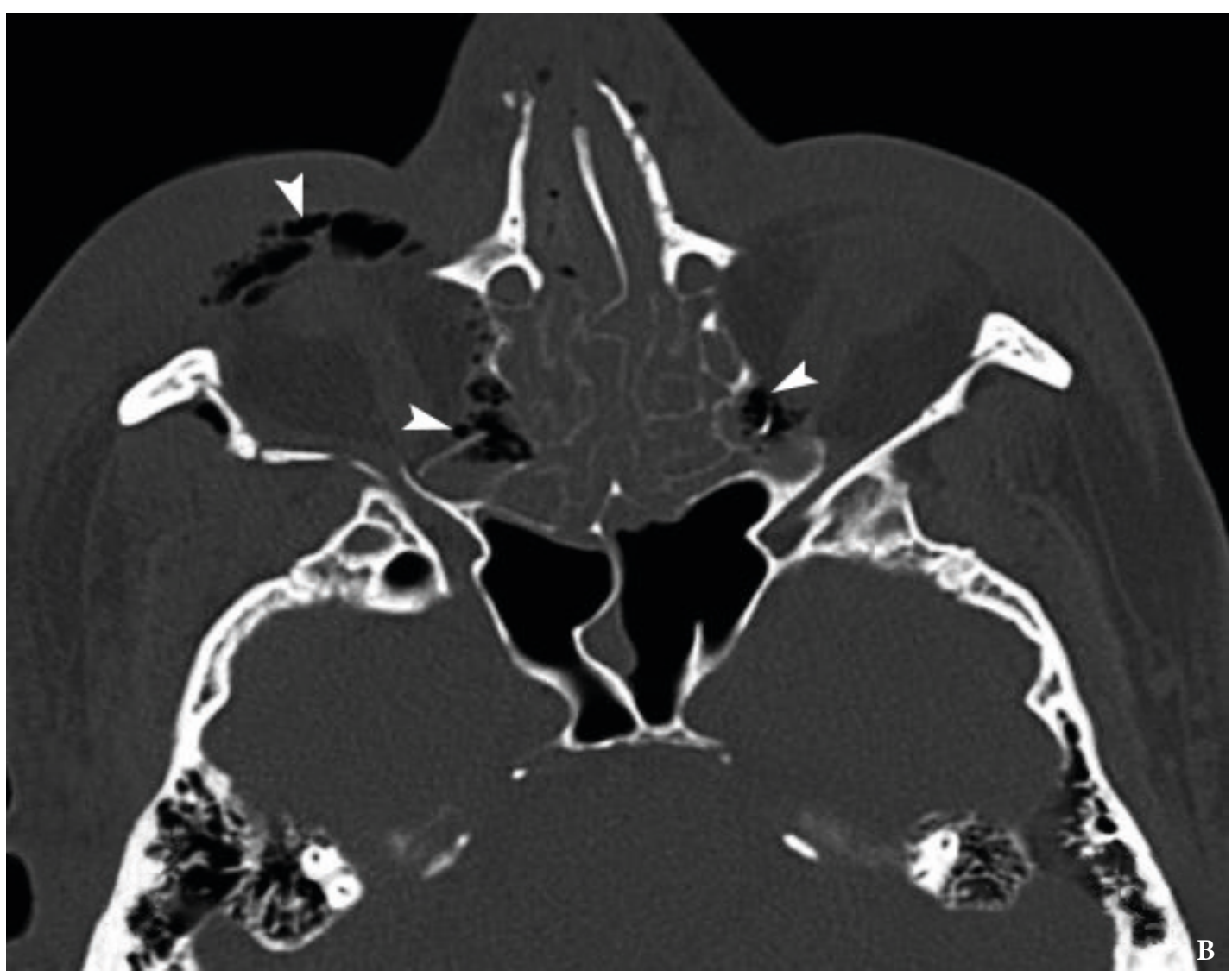

A

28-year-old male was transported to the emergency department after motor vehicle collision. Multislice computed tomography (CT) showed multiple facial fractures involving both maxillary sinus walls, walls (lateral, medial, upper and lower) of the right orbit, nasoethmoidal complex, right zygomaticofrontal suture, zygomaticomaxillary buttress, and pterygoid plates of sphenoid bone. Coronal (Panel A) and axial (Panel B) CT scans showed the soft tissues aeration (arrowheads) in the right buccal, periorbital, bilateral orbital regions, and intracranial. CT findings of the intracranially displaced bone fragments help in differential diagnosis between orbital emphysema and pneumocephalus (presence of air in the cranial cavity [in the subdural or intraventricular space]). Attenuation coefficient of the aerated areas varied from -872.1 to -730 Hounsfield units.

Post-traumatic emphysema (PTE) (synonyms: traumatic emphysema, fracture-induced emphysema) can follow the trauma of walls of the maxillary/frontal sinuses, naso-orbital-ethmoidal and zygomatico-maxillary complex. PTE may exacerbate due to sudden rise of pressure after sneezing or blowing the nose. Usually there is no need for some special treatment of the post-traumatic emphysema as it disappears spontaneously during a few days. Nevertheless, the development of acute cellulitis after the PTE appearance can be initiated in case of migration of infected particles from sinuses or traumatic agents (foreign bodies) with a help of air bubbles. The broad-spectrum antibiotic therapy prescribed during the fractures management will help to prevent possible emphysema-induced infection.

This case was managed by neurosurgery, oral-maxillofacial surgery; Opened reduction and internal fixation of facial fractures was done with prophylactic antibiotic coverage. Usually, conservative treatment is enough for intracranial air and its small areas can be observed and allowed to resorb. Unfortunately, the patient was lost to follow-up in late post-operative period. = DTJournal 


\section{TANTUM VERDE}

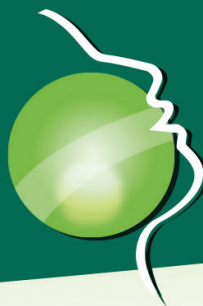

QUICK RELIEF FROM PAIN AND INFLAMMATION IN THE MOUTH AND THROAT'

\section{AN INTEGRAL COMPONENT OF THE TREATMENT OF PAIN AND INFLAMMATION IN THE ORAL CAVITY IN 60 COUNTRIES WORLDWIDE! ${ }^{2}$}

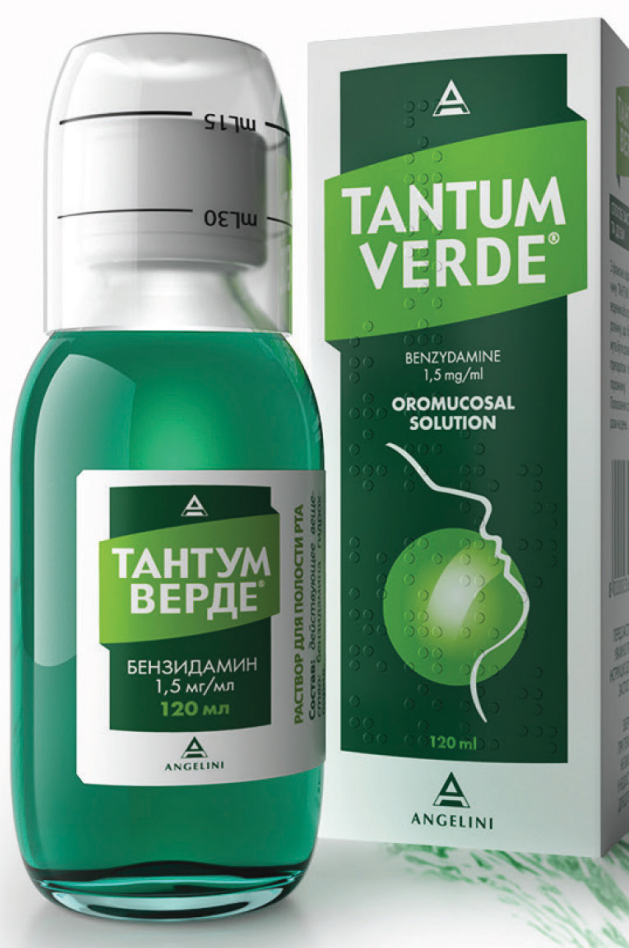

Reg. № UA/3920/01/01

\section{LOCAL ANESTHETIC AND ANTI-INFLAMMATORY EFFECT}

\section{- JAWS} FRACTURES ${ }^{3}$

- IMPLANTS PLACEMENT ${ }^{4}$

- WOUNDS OF ORAL CAVITY5
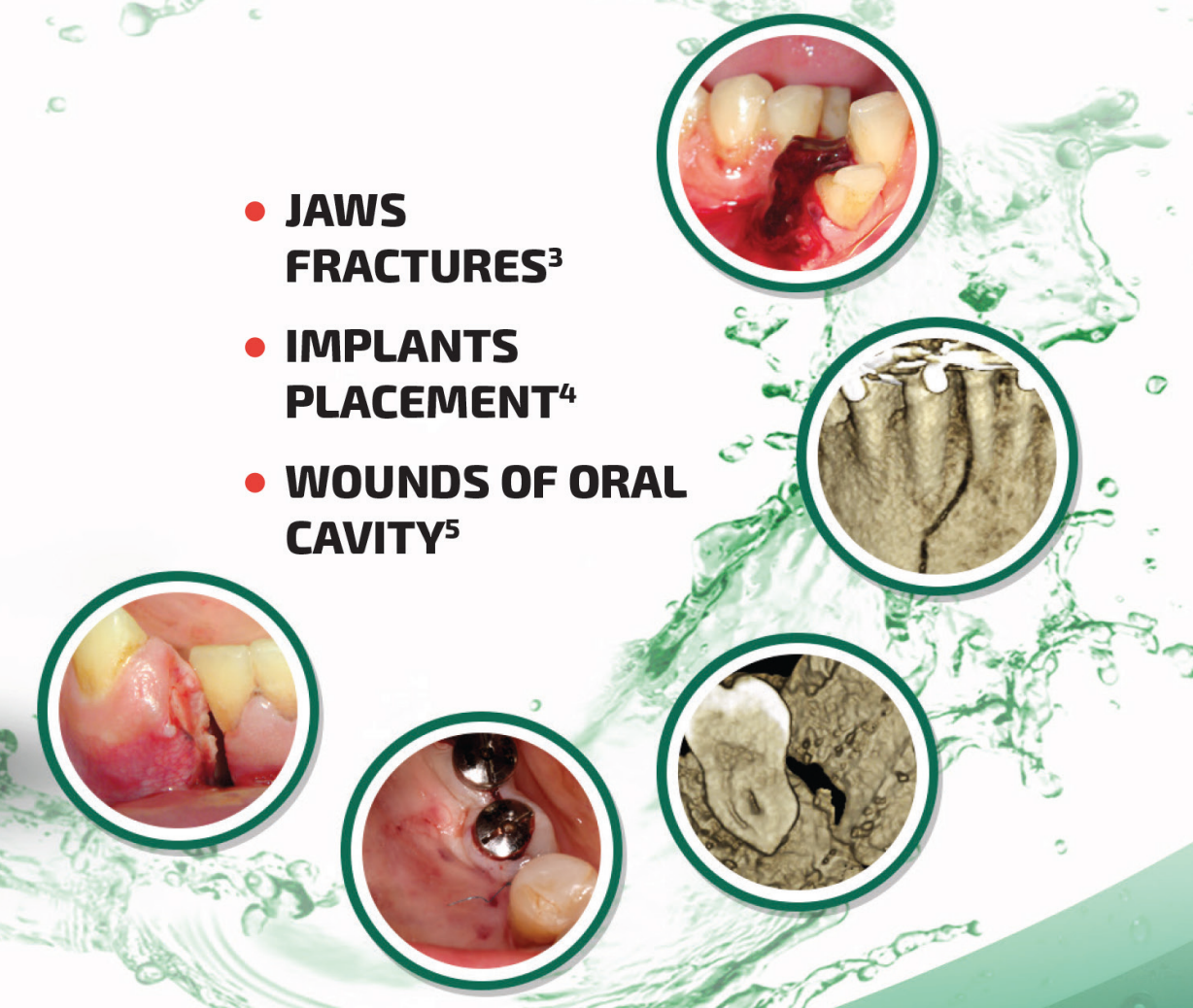

NAME OF THE MEDICINAL PRODUCT. Tantum Verde $0.15 \%$ mouthwash. QUALITATIVE AND QUANTITATIVE COMPOSITION. Each $100 \mathrm{ml}$ contains: active ingredient: benzydamine hydrochloride $0.15 \mathrm{~g}$ (equivalent to $0.134 \mathrm{~g}$ of benzydamine). Therapeutic indications. Treatment of symptoms such as irritation/inflammation including those associated with pain in the oropharyngeal cavity (e.g. gingivitis, stomatitis and pharyngitis), including those resulting from conservative or extractive dental therapy. Posology and method of administration. Pour $15 \mathrm{ml}$ of Tantum Verde mouthwash into the measuring cup, $2-3$ times per day, using it either at full concentration or ailuted. If diluted, add $15 \mathrm{ml}$ of water to the graduated cup. Do not exceed the recommended dosage. Contraindications. Hypersensitivity to benzydamine or to any of the excipient. PHARMACOLOGCAL PROPERIIES. Pharmacodynamic properties. Pharmacotherapeutic group: Stomatologic drugs: other agents for local oral treatment, AIC code: AOTAD2. Cinical studies demonstrate that benzydamine is effective in relieving suffering from locallsed irritation of the mouth and pharynx. In addition, benzydamine possesses a moderate local anaesthetic effect. Pharmacokinetic properties. Absorption. Absorption through the oropharyngeal mucosa is demonstrated by the presence of measurable quantities of benzydamine in human plasma. These levels are insufficient to produce systemic effects. Distribution. When applied locally, benzydamine has been shown to accumulate in inflamed tissues where it reaches effective concentrations because of its capacity to penetrate the epithelial lining. Information about medicines. Information for health care professionals for use in professional activities.

1 1нструкцін для медичного застосування лікарського засобу Тантум Верде

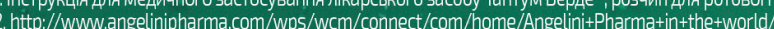

3. Тимофеев А.А. и др. "Особенности гигиены полости рта для профилактики воспалительных осложнений при переломах нижней челюсти". Современная стоматология 2015; (75):52-8.

4. 4,5. Tymofieiev 0.0. et al"Prevention of inflammatory complications upon surgeries in maxillofacial region". J Diagn Treat Oral Maxillofac Pathol, 2017; 1:105-12.

Clinical and CT images are courtesy of: Ievgen Fesenko (Department of Oral \& Maxillofacial Surgeny, PHEI "Kyiv Medical University," Kyiv, Ukraine), Oleg Mastakov ("SCIEDECE-Scientific Center of Dentistry \& Ultrasound Surgery" Kyiv, Ukraine) 